\begin{tabular}{|l|l|}
\hline Additional \\
Information
\end{tabular} \mid $\begin{aligned} & \text { NOTICE: This is the author's version of a work that was accepted for } \\
& \text { publication in Applied Geochemistry. Changes resulting from the } \\
& \text { publishing process, such as peer review, editing, corrections, structural } \\
& \text { formatting, and other quality control mechanisms may not be reflected in } \\
& \text { this document. Changes may have been made to this work since it was } \\
& \text { submitted for publication. A definitive version was subsequently } \\
& \text { published in Applied Geochemistry, Vol. 37, (2013). doi: } \\
& \text { http://doi.org/10.1016/j.apgeochem.2013.07.004 }\end{aligned}$




\title{
Geochemical modelling of petroleum well data from the Perth Basin. Implications for potential scaling during low enthalpy geothermal exploration from a hot sedimentary aquifer.
}

\author{
Domenik Wolff-Boenisch* and Katy Evans \\ Applied Geology, Curtin University, GPO Box U1987, Perth, 6845 Western Australia \\ *Domenik.Wolff-Boenisch@curtin.edu.au,0061-8-9266-2960
}

\begin{abstract}
Chemical analyses derived from petroleum exploration wells are notorious for their lack of key solute data and their potential to represent mixtures of reservoir and drilling fluids rather than pristine formation compositions. These drawbacks notwithstanding, they usually pose the only access to the reservoir geochemistry. Two literature protocols were applied to a dataset of incomplete major element analyses from 148 petroleum well samples from a database compilation of the Perth Basin whose deeper aquifers may serve as potential hot sedimentary aquifers for geothermal direct heat applications. The first protocol included a set of quality control criteria that reduced the number of relatively genuine formation well samples from the raw data pool by $71 \%$. The remaining well analyses are invariably $\mathrm{NaCl}$ solutions of low to medium alkalinity and an ionic strength only occasionally reaching seawater salinity. The low amount of total dissolved solids indicates the absence of extended evaporites in the North Perth Basin and the prevalence of meteoric water infiltration and circulation at depths.

The culled well samples underwent as a second protocol a forced equilibrium treatment to reconstruct in-situ reservoir concentrations of missing elements ( $\mathrm{Si}, \mathrm{Al}, \mathrm{K}$ ), organic acid anions and non-carbonate alkalinity, and $\mathrm{pH}$. The petroleum well samples were modelled to be in equilibrium with chalcedony (and kaolinite, albite, and paragonite) in the reservoir which yielded better convergence than using quartz instead. The derived formation temperatures correspond to geothermal gradients in the majority of cases between $25-35^{\circ} \mathrm{C}$, in accord with literature findings. Those wells drilled to depth $<1600 \mathrm{~m}$ returned questionably high geothermal gradients, an indication of incomplete mineral-fluid equilibrium. The measured $\mathrm{pH}$ (at ambient temperature) deviated in $>90 \%$ of the wells from the calculated $\mathrm{pH}$, either due to degassed $\mathrm{CO}_{2}$ or unaccounted acetate alkalinity.

The wells were further modelled to be undersaturated with respect to amorphous silica and anhydrite and not likely to experience scaling of any of these two phases during geothermal
\end{abstract}


production at depth $<3800 \mathrm{~m}$. For calcite, scaling predictions depend in how far bubbling and phase segregation can be suppressed. For the six different stratigraphies investigated here, calculated bubble points were low, indicating that pressurisation of the entire production and reinjection line seems viable. Based on a calcite growth model from the literature it is shown that, if bubble formation and concomitant carbonate flash scaling cannot be averted, the production well should be as shallow as the temperature requirements of the geothermal production allow for.

This study promotes the application of readily accessible protocols and a scaling model to deep well samples that may otherwise appear to have little geochemical value because of the way the samples were collected and handled. After data culling and treatment, insights into the geochemistry and scaling potential of deep clastic formations of the North Perth Basin that may hold the potential for geothermal exploitation as hot sedimentary aquifers can be gained.

\section{Introduction}

The need to find alternative energy sources has motivated widespread investigation and development of unconventional geothermal energy sources. In contrast to conventional geothermal systems, volcanic activity is absent in unconventional geothermal energy systems and the viability of thermal energy production depends on the type of heat source and permeability. Hot sedimentary aquifers (HSA) combine sufficient hot fluid volume and permeability to allow heat extraction on an economic scale for direct heat applications. They are more widespread than magma-related sources and technologically less challenging than engineered geothermal systems, such as hot dry rock sources. HSA are common worldwide and exploitation of geothermal energy from these sources has become a focus of attention in recent years, in response to the need to find alternative energy sources (Lund et al., 2011). The Perth Basin, Western Australia contains such HSA which are under scrutiny as a source for sustained geothermal heat extraction suitable for various energy intensive applications (Timms et al., 2012). Despite the relatively low temperature ( $\sim \leq 100^{\circ} \mathrm{C}$ at $3 \mathrm{~km}$ depth) of the geothermal waters permeating the sediments of the Perth Basin, there are already small-scale projects in place in the Perth metropolitan area with geothermally heated swimming pools but future plans include tapping a suitable HSA to run large-scale air conditioning systems and direct heating of water in desalination and mineral processing plants. Geothermal heat mining involves pumping geothermal waters to the surface via a producing well, extraction of heat in heat exchanger 
apparatus, and, in some regulatory environments, return of the fluids via an injection well to the subsurface. Technical issues associated with the chemical consequences of cooling and pressure decreases during geothermal heat extraction can be significant. From a geochemical point of view, the most notorious of these is scaling, the precipitation of an unwanted secondary phase out of the geothermal fluid due to changes in temperature, pressure, gas content, and redox state. Scaling may reduce the efficiency of the heat exchange process, cause loss of productivity and/or injectivity and may, depending on the nature of the secondary phase, even ruin the wellbore and/or permeability of the surrounding aquifer altogether. In order to gauge the potential for scaling during geothermal activities from HSA of the Perth Basin, geochemical modelling of petroleum well data from well completion reports compiled for the Perth Basin was performed. The first step involved sifting through the available data for representative chemical analyses followed by reconstruction of the in-situ composition of the sedimentary formation waters and final geochemical interpretation of the stability of key secondary phases, such as calcite, anhydrite, and amorphous silica. Findings are presented and discussed in the context of geothermal heat extraction from the Perth Basin. The information will aid effective exploitation of geothermal energy in the Perth Basin and anticipate the most likely scaling phases that may be encountered and dealt with during future direct heat production. The paper will also contribute to a wider appreciation of the possibilities and shortcomings of using HSA as a future means for low enthalpy direct heat applications.

\section{Geological Background}

The following brief introduction into the geologic setting and stratigraphy of the Perth Basin has been distilled from various sources (Cadman et al., 1994; Crostella, 1995; Crostella and Backhouse, 2000; Davidson, 1995; Laker, 2000; Mory and Iasky, 1996; Owad-Jones and Ellis, 2000; Playford, 1976). In this presentation, emphasis is placed on the Northern part of the Perth Basin because the culled dataset underlying this study stems, except for one sample (Gage Roads), from petroleum wells located in the Dandaragan Trough in the North Perth Basin (Fig. 1). The original dataset encompassed petroleum wells from the entire Perth Basin but it was mandatory to apply some quality control on the data, and wells from the Central and South Perth Basin were filtered out at this stage (cf. section 3.1 on data source and treatment). The subsequent stratigraphy section describes only the six units from which all the formation waters of the petroleum wells were sourced, viz. the Irwin River Coal Measures and Carynginia 
Formation from the Lower Permian, the Wagina Sandstone from the Upper Permian, the Basal Triassic Sandstone from the Lower Triassic, the Cattamara Coal Measures from the Lower Jurassic, and the Gage Sandstone from the Lower Cretaceous (Fig. 2).

\subsection{Basin Setting}

The Perth Basin is a north-south orientated elongate trough on the South Western Australian coastline (Fig. 1). It contains a succession of sediments ranging from marine to continental starting in the Silurian. The primary sediment volume was, however, deposited from the Early Permian to the Early Cretaceous (Fig. 2) in response to rifting, which concluded with the ultimate separation of India and Australia. Because of the intensive rifting over so many time periods, the Perth Basin is characterised by numerous, parallel, north-south trending (half)grabens and fault structures. Onshore sediments constitute roughly $50 \%$ of the basin surface area whereas the other half encompasses sediments offshore. The Perth Basin is flanked to the East by a north-south trending fault (Darling Fault) beyond which Precambrian granites and gneisses of the Yilgarn Craton occur. Physical weathering and erosion of these rocks provided the source for much of the sediments deposited into the subsiding (half)grabens of the Perth Basin. In the North Perth Basin, the most important sedimentary sink is the Dandaragan Trough, adjacent to the Darling Fault. This half-graben received up to 15,000 m of Silurian to Cretaceous sediments (Cadman et al., 1994) and it is here that nearly all petroleum wells which constitute the basis of this study are located (Figure 1). To the west, the Dandaragan Trough is limited by a number of north-south trending faults whereas to the south the Cervantes Transfer fault cuts off the Dandaragan Trough from the Bermullah Trough. One sampled well was drilled into the Vlaming Sub-basin (to the south) which lies offshore on the latitude of Perth.

\subsection{Basin Stratigraphy}

\subsubsection{Irwin River Coal Measures}

The Irwin River Coal Measures are an alternating sequence of sandstone, siltstone, carbonaceous shale, and claystone with beds of sub-bituminous coal. The sandstones in the Irwin River Coal Measures tend to be argillaceous with low permeabilities; nevertheless, gas is produced from the Irwin River Coal Measures in the Dongara field (cf. large red-green patch in enlargement in Fig. $1)$.

\subsubsection{Carynginia Formation}


The Carynginia Formation consists predominantly of dark micaceous and carbonaceous siltstone, and fine- to coarse-grained quartz sandstone, with thin beds of fine conglomerate (Mory and Iasky, 1996). In the Carynginia Limestone facies, primary porosity was occluded by clays and sparry calcite early during diagenesis (Cadman et al., 1994). Thin, discontinuous sandstones, sealed by shales and limestones, form valid gas reservoirs within the Carynginia Formation and are exploited in the Dongara field.

\subsubsection{Wagina Sandstone}

The Wagina Formation sandstones predominantly comprise arenites, with quartz, K-feldspar and minor plagioclase as primary minerals and kaolinite and illite-smectite to chlorite-smectite pore fillings (Laker, 2000). Despite its limited areal distribution, the Wagina Sandstone is an important hydrocarbon reservoir in the Dongara field.

\subsubsection{Basal Triassic Sandstone}

The Basal Triassic Sandstone consists predominantly of bioturbated medium to coarse grained quartz-rich sandstone with interbedded limestone, carbonaceous siltstone, and minor thin pebble bands. The main diagenetic materials in the Basal Triassic Sandstone are common quartz and kaolinite, with trace siderite and calcite. Diagenesis in the reservoir sandstones of the Irwin River Coal Measures and Carynginia Formation is quite similar to the Dongara Sandstone (OwadJones and Ellis, 2000). The Basal Triassic Sandstone is a primary exploration target for hydrocarbons in the North Perth Basin..

\subsubsection{Cattamarra Coal Measures}

The upper unit of the Cockleshell Gully Formation consists of quartz-rich sandstones with interbedded shales, claystones, siltstones and seams of coal and is termed the Cattamarra Coal Measures Member. The sandstones are pale grey, often clayey, mostly medium to coarse grained and are present in beds up to $50 \mathrm{~m}$ thick (Davidson, 1995). The siltstones and shales are dark grey, sometimes carbonaceous, and occur in beds up to 30m thick. The main diagenesis evident in the reservoir sandstone consists of common quartz overgrowths and kaolinite, trace to common calcite, and trace siderite cement (Owad-Jones and Ellis, 2000). Some of the best quality hydrocarbon reservoirs in the Perth Basin occur in the Cattamarra Coal Measures (Cadman et al., 1994). 


\subsubsection{Gage Sandstone}

The Gage Sandstone Member consists of interbedded sandstones, siltstones and shales.. The interbedded siltstones and shales are pale grey to grey brown in colour, slightly micaceous and commonly in beds less than $6 \mathrm{~m}$ thick. In the Vlaming Sub-basin offshore, oil was recovered in the basal transgressive sands of the Gage Sandstone Member.

\section{Methods}

\subsection{Data source and treatment}

The basis for the geochemical reconstruction and modelling is a database comprising 148 chemical analyses collated from well completion reports of petroleum exploration wells drilled from the 1960s to 1980s in the Perth Basin around the metropolitan Perth area to evaluate the potential for economic hydrocarbon extraction. As can be seen in Figure 1b, few well samples originated from the upper central part of the Perth Basin (Bootine and Gingin). From nearly all of the wells, gas and/or oil was produced but most of them have been abandoned and plugged in the meanwhile (Crostella, 1995). Fluid sampling conditions under these activities are not ideal, a fact compounded by the routine practice to carry out only a so-called 'standard' analysis, where merely $\mathrm{Ca}, \mathrm{Mg}, \mathrm{Cl}, \mathrm{SO}_{4}$, and $\mathrm{HCO}_{3}$ are determined analytically whereas $\mathrm{Na}$ is calculated stoichiometrically as the difference between the sum of the anions and the sum of the cations, ignoring K completely. This approach leads to analytical errors. Furthermore, these construed chemical analyses may not necessarily represent pristine formation water compositions vital for accurate modelling but a mixture including water and non-water based drilling fluids deployed during the drilling phase. As a consequence, it is imperative to apply consistent quality control protocol to the available data. Culling criteria that have been applied to the present data set to winnow representative formation water analyses from the bulk have been taken from Hitchon and Brulotte (1994). Criteria sufficient to cause exclusion of the data, known as flags, include:

1) Incomplete major ion analysis, any of these ions missing ( $\mathrm{Ca}, \mathrm{Mg}, \mathrm{Na}, \mathrm{Cl}, \mathrm{SO}_{4}, \mathrm{HCO}_{3}$ )

2) Mg values larger than Ca values

3) $\mathrm{pH}$ lower than 5 or higher than 10

4) $\mathrm{OH}$ and/or $\mathrm{CO}_{3}$ reported

5) Negative Na reported

6) Fluid density (spec. gravity) lower than water (1.0)

7) Ionic balance exceeds specific limits (see below). 
The first flag ensures that only complete analyses are retained for further evaluation. Note that potassium is not considered a vital solute whose absence or suspiciously high concentration does not justify exclusion of the analysis from the data set. The second flag removes analyses where precipitation of $\mathrm{CaCO}_{3}$ may have taken place due to a variety of causes, for example, long time spans between sampling and analysis. The third flag indicates contamination of the formation fluids due to acid and cement washing or the presence of mud filtrate that results in either anomalously low or high $\mathrm{pH}$. Formation waters which are contaminated by cement wash or mud filtrate will have high $\mathrm{pH}$ values (>10), and/or reported contents of $\mathrm{CO}_{3}$ or $\mathrm{OH}$. Therefore, the fourth flag is intended to remove those mud contaminated samples where the contamination was not sufficient to result in a $\mathrm{pH}>10$ but which display appreciable $\mathrm{CO}_{3}$ alkalinity. Caution must be exerted to not mistake cement $\mathrm{CO}_{3}$ alkalinity for the total reservoir alkalinity which is often recorded as $\mathrm{CaCO}_{3}$. The fifth flag discards analyses of calculated negative Na concentrations which indicate severe analytical problems. The penultimate flag comes into action when the density is lower than 1 , for which a poor determination or contamination with organic matter, including alcohol (sometimes used as a drilling mud additive) could be responsible. Finally, in those cases where Na was measured instead of being stoichiometrically determined ionic charge balance can be a further quality indicator of the analysis. The net ionic charge balance was calculated by subtracting all anion (TZ) from all cation concentrations $\left(\mathrm{TZ}^{+}\right.$) on a (milli)equivalent basis and dividing the sum by all positive charges: $\left(\mathrm{TZ}^{+}-\mathrm{TZ}^{-}\right) / \mathrm{TZ}^{+}$. Analyses with net ionic charge balance higher than $20 \%$ were rejected.

The aforementioned criteria were applied automatically through an 'IF' clause implemented into an MS Excel ${ }^{\mathrm{TM}}$ worksheet containing the raw data. Additionally, certain methods of production were rejected manually (e.g., swabs, gas lifts, blow downs) as were all those analyses that did not provide a sampling interval or information on the geologic formation. The latter steps reject samples that cannot be assigned a specific aquifer or formation, including water well samples.

\subsection{Thermodynamic considerations}

Geochemical modelling of the culled data was performed with PHREEQC 2.18.3 (Parkhurst and Appelo, 1999) using the Lawrence Livermore 'Ilnl' database (version thermo.com.V8.R6.230).. From available PHREEQC databases, Ilnl is the only one providing 
thermodynamic equilibrium constants, enthalpies of reaction, and even analytical expressions for the temperature dependence of equilibrium constants related to acetate-metal reactions which will be an important part of the following geochemical modelling. Furthermore, llnl conveniently contains thermodynamic data of diagnostic equilibrium minerals such that no mixing of different thermodynamic datasets to model the reservoir geochemistry was required. As the IInl database does not take the effect of pressure on equilibrium constants into account, it was modified to improve the calculation of the solubility product $\left(\mathrm{K}_{\mathrm{sp}}\right)$ for two key scaling phases, calcite and anhydrite, as a function of (formation) pressure. The pressure corrected $\mathrm{K}_{\mathrm{sp}} *$ were based on the findings of Macdonald and North (1974) for calcite and Blount and Dickson (1969) for anhydrite, respectively. Figure 3 was drawn from the $K_{s p}$ values provided by Macdonald and North (1974) for three temperatures and clearly depicts how $K_{\mathrm{sp}}$ of calcite varies with pressure. In the hydrostatic pressure range expected in this study (grey box, based on the known sampled depth interval) the pressure effect may cause a significant $0.4 \log$ unit rise in $K_{\mathrm{sp}}$ from 1 to 400 bar. The $\mathrm{K}_{\mathrm{sp}}$ for calcite inserted into PHREEQC was based on the linear least square fit at $23 / 25^{\circ} \mathrm{C}$ in Figure 3 at the estimated individual formation pressure. As the slopes for the two temperatures are parallel, it indicates that the shift in the y-intercept is a result of the temperature effect on $\mathrm{K}_{\mathrm{sp}}$ which is already taken care of in PHREEQC through the enthalpy of reaction derived from the van't Hoff equation. That is, the $I l n l$ database referring to the 'log_K' of calcite was overridden by using the key word 'solution_species' where a modified pressure-dependent $\mathrm{K}_{\mathrm{sp}}$ was entered (at $25^{\circ} \mathrm{C}$ ) while the unchanged enthalpy of reaction provided a recalculated $\mathrm{K}_{\mathrm{sp}} *$ as a function of the temperature at depth.

The pressure effect on $\mathrm{K}_{\mathrm{sp}}$ is somewhat smaller for anhydrite. He and Morse (1993) predicted a reduction of only 0.2 log units in $\mathrm{K}_{\mathrm{sp}}$ during ascent from $6000 \mathrm{~m}$ depth to the surface, in a 6 molal $\mathrm{NaCl}$ solution at a constant temperature of $150^{\circ} \mathrm{C}$. At lower ionic strength, a larger deviation is calculated with the formula provided by Blount and Dickson (1969) which yields a 0.7 log units larger $\mathrm{K}_{\mathrm{sp}}$ for anhydrite in a pure water solution at $150^{\circ} \mathrm{C}$ and $600 \mathrm{bar}$, compared to 1 bar. Given the relatively low ionic strength of the petroleum well analyses, the equation from Blount and Dickson (1969) was used to calculate $\mathrm{K}_{\mathrm{sp}}$ at formation pressure and temperature and inserted into PHREEQC in the same way as described above. Silica is also considered a potential scaling phase in this study. Willey (1974) studied the effect of pressure on the solubility of amorphous silica in seawater at $0^{\circ} \mathrm{C}$. Based on her findings, the maximum pressure effect on log 
$\mathrm{K}_{\mathrm{sp}}$ in this study would be not more than $0.08 \log$ units at 400 bar; this pressure effect was hence neglected.

\subsection{Formation water reconstruction}

Formation water analyses as part of oil and gas exploration efforts are infamous for their lack of vital information on key solutes, such as $\mathrm{Al}, \mathrm{Fe}, \mathrm{Si}$, and any organic acid anion. Besides, due to the nature of the sampling (drill stem tests in the majority of cases) the sample may contain remnants of drilling fluids and may have degassed $\mathrm{CO}_{2}$ with the effect of changing $\mathrm{pH}$ during uplift and leading subsequently to non-representative $\mathrm{pH}$ field or lab determinations. One solution to this dilemma is to use the tenet of chemical equilibrium of formation waters with specific diagenetic minerals in the sedimentary host rock. Secondary phases start precipitating from a pore fluid when the latter becomes saturated with these phases and a dynamic, tightly temperature dependent equilibrium between fluid and phase evolves. This principle of mineralfluid interaction reaching equilibrium, which is the basis of geothermometry (Giggenbach, 1981, 1988), has been extensively studied in sedimentary settings (Bjørlykke and Gran, 1994; Connolly et al., 1990; Furlan et al., 1995; Garrels and MacKenzie, 1972; Hanor, 1994; Hutcheon et al., 1993; Michael and Bachu, 2002; Osborne et al., 1994; Stueber and Walter, 1991; Yardley et al., 2003) and successfully applied to reconstruct in-situ compositions of sedimentary formation waters (Bazin et al., 1997; Palandri and Reed, 2001). Especially the latter of these last two references provides a detailed protocol that can be applied to the scarce chemical information of the petroleum well dataset to stitch together a consistent picture of the likely chemical composition of the geothermal waters permeating the Perth Basin. The assumptions laid out in that reference are briefly introduced below and comprise the backbone of the following presentation of results and ensuing discussion. It is beyond the scope of this study to reproduce the in-depth discussion of the reasons and constraints underlying these assumptions and hence the reader is referred to Palandri and Reed (2001). Required assumptions for reconstruction of the reservoir fluids at formation depths and temperatures are as follows:

a) Missing reservoir temperatures, $\mathrm{Si}$ concentrations, and $\mathrm{Al}$ concentrations are approximated using the 'FixAl' approach described by Pang and Reed (1998). This approach involves assuming equilibrium in the formation with chalcedony or quartz and muscovite or kaolinite to fix the $\mathrm{Si}$ and $\mathrm{Al}$ concentration, respectively. 
b) The potential $\mathrm{CO}_{2}$ loss during sampling is taken care of for by adding back $\mathrm{CO}_{2}$ until equilibrium in the formation with calcite is attained.

c) The absence of measurements of organic acid anions and their potential effect on the alkalinity is addressed by representing all organic acids with acetic acid as a proxy and adding acetate and removing bicarbonate while maintaining total alkalinity at the measured value.

If mineral-fluid equilibria for appropriate diagnostic mineral phases is reached in the reservoir then the saturation lines of the chosen phases will converge at a saturation index (SI) of zero at a temperature deemed to record the reservoir temperature. Adjustments of $\mathrm{pH}$ (through the $\mathrm{pCO}_{2}$ ) and total alkalinity (via substitution of acetate alkalinity for bicarbonate alkalinity) will result in modifications to the saturation indices of the diagnostic phases to attain equilibrium values.

The procedure of how these key steps are implemented is illustrated for one petroleum well (Warr1d, Table 1) in Figure 4. In general, no reservoir temperature of any well and thus depth interval could be retrieved from the well completion reports. Since this vital parameter was apparently not measured the first step of the reconstruction procedure involves creating a graph where saturation indices of specific diagenetic phases are plotted over the temperature range of interest. The particularity of this plot is that equilibrium with a specific Al phase over the entire temperature range is forced, and this is what Pang and Reed (1998) called 'FixAl'. This term converts to 'FixAlSi' in this study because neither $\mathrm{Al}$ nor Si concentrations were available for the petroleum wells and thus equilibrium with a specific Si and Al phase, respectively had to be fixed over the entire temperature range to make sure the unknown reservoir temperature is covered. In Figure 4a, quartz and kaolinite were first chosen, complemented with saturation indices calculated for the diagenetic minerals chalcedony, albite, muscovite, K-feldspar, calcite, and paragonite. Palandri and Reed (2001) found these minerals as invariably good diagnostic indicators for equilibrium in their study on the reconstruction of geographically diverse sedimentary reservoir waters, with robust Gibbs free energy data to calculate saturation indices. Apart fom paragonite, these minerals are also the principal components of the sediments in the Dandaragan Trough and mentioned in the descriptions of the mineralogical composition of the well cores (see stratigraphic description above). The diagenetic mineral illite was also added, although its diagnostic value is less compelling because of thermodynamic uncertainties related 
to its amply varying chemical composition. As can be seen in Figure 4a, calcite does not converge to equilibrium at any realistic temperature under these conditions. The strategy then is to try different combinations of saturated phases and vary $\mathrm{CO}_{2}$ pressure and/or acetate alkalinity with the aim of getting the saturation lines to converge at a reasonable temperature which will be adopted as reservoir temperature. Adding $\mathrm{CO}_{2}$ back to the solution by applying $\mathrm{CO}_{2}$ pressure will decrease the $\mathrm{pH}$ and thus the supersaturation not only of calcite but also of the aluminosilicate minerals. However, lowering the $\mathrm{pH}$ would only shift all equilibrium lines towards lower SI without improving convergence; rather part of the total alkalinity was converted into acetate alkalinity to reduce principally the calcite supersaturation. Note that only bicarbonate concentrations were reported for the petroleum wells and had to be recalculated to give total alkalinity (Table 1). Trying iteratively different acetate percentages improves the convergence of calcite with paragonite at equilibrium $(\mathrm{SI}=0)$ but not with albite (Fig. $4 \mathrm{~b})$. If chalcedony is chosen as initial equilibrium phase to buffer the reservoir silica activity instead of quartz (Fig. 4c) a much better fit is achieved through the same acetate-alkalinity treatment (Fig. $4 d)$. Figure $4 \mathrm{e}$ corresponds to Figure $4 \mathrm{~d}$ in that the $\mathrm{Al}$ and $\mathrm{Si}$ concentrations found at the approximated equilibrium temperature in Figure 4d were introduced into PHREEQC and the forced equilibrium with chalcedony and kaolinite removed. The tight saturation lines knot in Figure $4 \mathrm{e}$ indicates an equilibrium formation temperature of $98^{\circ} \mathrm{C}$. Note that no K-bearing mineral (e.g. K-feldspar, muscovite) converges at these temperatures to help constrain convergence as these phases seem to be supersaturated in the formation, due to high $\mathrm{K}$ concentration of the sample. If equilibrium with K-feldspar (together with chalcedony and kaolinite) was nonetheless forced, the same acetate adjustment would also yield equilibrium with illite and result in an equilibrium temperature of $97^{\circ} \mathrm{C}$ (Fig. 4f). Note that in this case there was no need for $\mathrm{CO}_{2}$ to be added back meaning that no $\mathrm{CO}_{2}$ had previously degassed during sampling. An example where the $\mathrm{CO}_{2}$ amount had to be readjusted is given in chapter 4.2 (Fig. 9).

$\mathrm{Al}, \mathrm{Si}$, and occasionally $\mathrm{K}$ concentrations, as well as formation $\mathrm{pH}$, acetate fractions and reservoir temperatures for all analyses in Table 1 were determined in this manner. Uncertainties associated with this technique are not discussed in Palandri and Reed (2001) but the authors managed to extrapolate with high confidence $\left(r^{2}=0.98\right)$ a geothermal gradient based on a correlation of reconstructed reservoir temperatures and well depth for thirteen samples. In our 
study, however, because of the lack of equilibrium with K-minerals the equilibrium temperature is less constrained and thus more uncertain. Besides, visual assessment of line convergence, such as in Figure 4 allows for some leeway. More importantly, reconstruction depends on the thermodynamic database underlying the saturation calculations. Dethlefsen et al. (2011) did scenario simulations on groundwater-mineral assemblage interactions using the four PHREEQC databases (phreeqc, wateq, minteq, and llnl) and found an amount of fixed $\mathrm{CO}_{2}$ up to a factor of six larger when using wateq and minteq, respectively compared to llnl. This maximum discrepancy translates into a possible variation of $\mathrm{pCO}_{2}$ up to 0.8 log units (=factor six) yielding equilibrium temperatures that could potentially vary up to $25-30^{\circ} \mathrm{C}$. So the implementation of a different database other than Ilnl together with individual visual perceptions or personal criteria as to when exactly perfect equilibrium match between the single phases has been attained (the lines do not all converge to exactly 0.0 SI at exactly one temperature) will invariably result in variation in the equilibrium and thus formation temperature that could potentially reach tens of degrees deviation.

\section{Results and Discussion}

\subsection{Overview of formation water compositions}

Applying the quality control criteria to the Perth Basin database collation reduced the number of accepted analyses by $70 \%$, from 148 to 45 . Two more samples were excluded because of a very high concentration of total dissolved solids (TDS), likely the result of either contributions from drilling operations or a time gap between sampling and sample analysis which permitted evaporation. An extreme TDS cannot per se be a criterion to flag a sample as this parameter depends on the specifics of the basin genesis and the presence of evaporites and/or frequency of seawater intrusions, explaining why these two samples had not been detected during the application of the culling protocol. However, their TDS of 166,000 and 254,000 mg/L, respectively are not only extraordinarily high; in the latter case the determined TDS drops an order of magnitude to 21,000 ppm within a mere $24 \mathrm{~m}$ vertical depth. Applying a statistical outlier test (Grubbs and Beck, 1972) to the lower of both TDS values confirmed it as an outlier compared to the bulk TDS of the North Perth Basin. By extension, the sample with the highest TDS value was discarded, too.

The chemical composition of these 43 sifted samples has been tabulated together with the sampling depth and geologic formation and period (Table 1). Note that not all samples belong to 
different depth intervals; the 43 culled samples represent 31 discreet depth intervals from 20 individual wells. However, solute chemistry and/or $\mathrm{pH}$ within an interval are sufficiently variable to warrant their treatment as individual samples rather than being averaged as representative of the sampled interval or discarded as duplicate. Interestingly, a rejection percentage of $70 \%$ is very similar to the $69 \%$ reported by Hitchon and Brulotte (1994) on their quality analysis of over 141,000 formation water samples from the entire Western Canadian Sedimentary Basin. The highest numbers of analyses from the Perth Basin were discarded because of incomplete major element analysis (51 \%) followed by missing sampling intervals (23\%) and reported $\mathrm{OH} / \mathrm{CO}_{3}$ values (22\%) whereas no data set showed negative Na concentrations or fluid densities lower than one. It is noteworthy that nearly half of the rejected samples had multiple flags.

The remaining data were inserted into a Piper diagram to enable an overview of elemental trends and to help establish specific sub-groups. As can be seen in Figure 5, the vast majority of samples are $\mathrm{NaCl}$ dominated fluids. In the lower right triangle all but four samples show chloride contents making up at least $75 \%$ of the total anion load and only five samples have $\mathrm{Na}(+\mathrm{K})$ contributions $<75 \%$ (lower left triangle). As a result, the data points cluster in the centre-right diamond in the middle graph. Those few samples that do not follow the general trend stem from three different depth intervals within the petroleum well Gingin1 from the Cattamarra Coal Measures which have been marked with a cross. According to the Piper plot, the North Perth Basin consists predominantly of $\mathrm{NaCl}$ fluids. Irrespective of the sampled stratigraphy, the formation waters exhibit by and large a low TDS and their ionic strength reaches seawater salinity ( 0.7 molal) only in two cases (Figure 6). Thus, the corresponding aquifers from which the samples were retrieved can be classified as predominantly brackish (5,000-30,000 ppm) with few saline exceptions (30,000-50,000 ppm) and no brines (>50,000 ppm). The low salinities point to a predominance of meteoric pore water influx for the sampled stratigraphies. The six major stratigraphies on which the entire petroleum well data rely are found at varying unrelated depths because the North Perth Basin encompasses numerous faults and trenches (Fig. 1). Thus, there is no compelling trend between TDS and depth or stratigraphy, respectively in Figure 6 although such a trend is often cited in the literature, e.g. Kharaka and Hanor (2003).

Lithologies in the Perth Basin can vary on the order of $\mathrm{cm}$ to few metres vertical scale which indicates complex changes of sedimentary depositional environments in time and space (Timms et al., 2012). This diversity of lithologies renders any attempt of attribution of formation waters 
to a particular lithofacies speculative because fluid samples, whose compositions are intimately linked to the composition of the rocks they have equilibrated with were taken over a depth range of several metres, in few cases reaching tens of metres that may encompass different depositional environments. Nevertheless, plotting the major cations versus the chloride content, on a molar basis, identifies those well samples (and by extension stratigraphies) with possible influences from seawater incursions and infiltrations or evaporite dissolution (Fig. 7). The former is characterised by a specific constant molar ion ratio, the so-called seawater dilution line (SWDL, dashed slope) whereas the latter displays a slope of either one for the monovalent cations or a slope of 0.5 for the earth alkaline metals (solid lines in Fig. 7).

Except for the Na-Cl plot, an overwhelming contribution from pure evaporites, such as homogeneous sylvite or bischofite layers to the solute load can be ruled out because the data do not plot on the solid lines. This observation is consistent with the absence of evaporites in the geologic and petrologic description of the North Perth Basin and the overall low ionic strength of the waters. Most of the $\mathrm{Na}-\mathrm{Cl}$ data lie either on the unity slope or the SWDL, which, given the predominance of $\mathrm{NaCl}$ in seawater, is similar (0.86). The observed 1:1 relationship in the concentrations of sodium versus chloride is attributed to rock buffering and general mineral-fluid exchange reactions and equilibration during the diagenetic evolution of the basinal waters (Hanor, 2001) rather than a direct contribution from dissolving halite. This supposition is corroborated by the significant losses of Mg and gains of Ca compared to the SWDL, a result of rock mediated dissolution-precipitation processes in the clastic reservoir. There are 13 samples from 8 individual depth intervals in the $\mathrm{Na}-\mathrm{Cl}$ plot that fall on the SWDL slope. Of these depth intervals, only for the well Gage Road1 can a link to seawater infiltration be evoked unambiguously because the well is sourced by the Gage Sandstone located offshore in the Vlaming Sub-basin and displays exactly the same ionic strength as that of typical seawater ( 0.7 molal) and matching TDS (Fig.6, Table 1).

Six samples in the $\mathrm{K}-\mathrm{Cl}$ plot display high $\mathrm{K} / \mathrm{Cl}$ ratios approaching a slope close to unity which are offset from the origin. Five samples stem from the Warradong1 well (Table 1) with a narrow K concentration range between 2800 and $3200 \mathrm{mg} / \mathrm{L}$. Given that the Warradong1 well sampled three different stratigraphies from Lower Permian to Lower Triassic, it seems more likely that the constant and high $\mathrm{K}$ values are artefacts from drilling fluids rather than genuine. The same applies to the sixth data point (well Bootine1) whose K concentration from the 'Cattamarra Coal 
Measures’ even surpasses its Na concentration, amounting to $5700 \mathrm{mg} / \mathrm{L}$. In contrast, all Gingin1 well samples taken at similar depth from the same stratigraphy display K concentrations $\leq 120$ mg/L, 50 times less than Bootine1. Although $\mathrm{KCl}$ is a ubiquitous drilling fluid component, high potassium concentrations or $\mathrm{K} / \mathrm{Na}$ ratios did not constitute a flag for sample exclusion during quality control. This explains why these six samples exhibit not only such high K concentrations but are also parallel to the unity slope.

The anion-chloride ratios for the key anions $\mathrm{HCO}_{3}$ and $\mathrm{SO}_{4}$ are not shown because plots of anion-chloride concentration trends are unlikely to reflect original porewater concentrations. $\mathrm{HCO}_{3}$ is heavily enriched due to the presence of $\mathrm{CO}_{2}$ and/or dissolution of carbonates and the relative depletion of $\mathrm{SO}_{4}$ can go back to more than one reason that cannot be assessed in this study, for example, sulphate precipitation of any of the phases anhydrite, barite, gypsum or a combination thereof coupled with bacterial and/or thermochemical sulphate reduction (Goldstein and Aizenshtat, 1994; Hao et al., 1996).

\subsection{Geochemical and thermal formation water reconstruction}

During the geochemical reconstruction of the petroleum well data, the following consistent observations were made. For those wells with a relatively shallow sampling interval < 1600 m, reconstruction yielded reservoir temperatures corresponding to unusually high geothermal gradients. As an example, Allanooka1 is the shallowest of the culled wells with an upper sampling interval commencing at $860 \mathrm{~m}$. Based on heat flow due to radioactive decay coupled with thermal conductivity, the range of reasonable geothermal gradients for the Perth Basin was estimated to lie between 17 and $35^{\circ} \mathrm{C} / \mathrm{km}$ (Timms et al., 2012), with lower values more representative for the South Perth Basin and upper values more consistent with the Central Perth Basin. For the Dandaragan trough in particular, Mory and Iasky (1996) postulated a uniform geothermal gradient of $20^{\circ}-25^{\circ} \mathrm{C} / \mathrm{km}$. Thus, assuming a geothermal gradient of $30^{\circ} / \mathrm{km}$, which bridges the afore-mentioned upper geothermal gradient limits, coupled with a surface temperature of $20^{\circ} \mathrm{C}$ results in a formation temperature around $46^{\circ} \mathrm{C}$ for Allanooka1 where no convergence between a silica, carbonate and Na bearing phase is observed (Figure 8a). This lack of convergence indicates equilibrium between the diagenetic minerals was not attained. Adding $\mathrm{CO}_{2}$ back would only result in a shift of the saturation lines towards higher temperature and was therefore not considered. In contrast, converting $50 \%$ of the total alkalinity into acetate alkalinity yields equilibrium with the four diagnostic phases, chalcedony, kaolinite, albite, and 
calcite (Figure 8b). However, the reconstructed reservoir equilibrium temperature of $59^{\circ} \mathrm{C}$ corresponds to a geothermal gradient of $45^{\circ} \mathrm{C} / \mathrm{km}\left(=45^{*} 0.86+20\right)$ which is quite high for the North Perth Basin. Also, paragonite is not in equilibrium in the formation at the reconstructed temperature although this indicator mineral was integral part of any equilibrium reconstruction at higher temperatures in the other petroleum wells. Both observations indicate poorly or only partially achieved equilibrium in the shallower regions of the reservoir below a certain threshold temperature.

Another example is the Mount Horner 2 well (MH2a,b in Table 1) where at $1208 \mathrm{~m}$ depth a dubious geothermal gradient of $41^{\circ} \mathrm{C} / \mathrm{km}$ is inferred $\left(=41^{*} 1.2+20\right)$ which is reduced to a more coherent value of $29^{\circ} \mathrm{C} / \mathrm{km}$ at $1555 \mathrm{~m}(=29 * 1.55+20)$. This assumption of incomplete equilibrium because of kinetic barriers at shallow depth does not run counter to the tenet of chemical equilibrium between reservoir waters and host rock diagenetic minerals applied by Pang and Reed (1998) and Palandri and Reed (2001) as their reconstruction used well data with reservoir temperatures starting at 75 and $80^{\circ} \mathrm{C}$, respectively. In this study, samples taken at depth shallower than $\sim 1600 \mathrm{~m}$ showed no satisfactory convergence for paragonite and returned questionably high geothermal gradients. This depth corresponds to formation temperatures around $68^{\circ} \mathrm{C}\left(=30^{*} 1.6+20\right)$ based on an average geothermal gradient of $30^{\circ} \mathrm{C} / \mathrm{km}$.

Another general trend for the petroleum data set is better convergence using chalcedony (together with kaolinite) for the formation water reconstruction than quartz (and kaolinite or muscovite). This statement is corroborated by Figure 4 on a medium temperature well but also holds for a higher temperature well (Bootine1, Figure 9). Equilibrium with quartz (and kaolinite) does not converge convincingly at anticipated reservoir temperatures around $130^{\circ} \mathrm{C}$ (Fig. 9a) whereas forcing equilibrium with chalcedony (and kaolinite) instead (Fig. 9b) results in improved mineral convergence and equilibrium at $125^{\circ} \mathrm{C}$ (Fig. 9c). In both cases, reconstruction included applying a specific, iteratively determined $\mathrm{pCO}_{2}$ to add $\mathrm{CO}_{2}$ back to the solution to lower the $\mathrm{pH}$ from a measured 8.15 to modelled 5.4, without the need for additional alkalinity adjustment. $125^{\circ} \mathrm{C}$ appears to be a high saturation temperature for chalcedony, more appropriate for quartz as equilibrium with quartz in sedimentary reservoirs was reported already at temperatures $>70^{\circ} \mathrm{C}$ (Kharaka and Hanor, 2003) and in the range $100-120^{\circ} \mathrm{C}$ (Bazin et al., 1997). Furthermore, quartz seems the obvious mineral buffer for the silica activity in quartz bearing 
sediments. However, only four out of 31 sampled depth intervals in this study reach reservoir temperatures $>105^{\circ} \mathrm{C}$, whereas for the bulk of sample intervals, derived equilibrium temperatures lie between $70-90^{\circ} \mathrm{C}$. Quartz equilibrium and thus the possibility of quartz geothermometry is fully realised at temperatures $\geq 180^{\circ} \mathrm{C}$ whereas at lower temperatures equilibrium with chalcedony becomes important (Gupta and Roy, 2007). The better convergence with chalcedony in this study is in agreement with Palandri and Reed (2001) who also reported chalcedony saturation in fluids from formations containing diagenetic quartz at equilibrium temperatures around $100^{\circ} \mathrm{C}$. Consequently, the diagenetic presence of quartz does not necessarily indicate that the silica activity in solution is buffered with this phase. Equilibrium with metastable chalcedony that formed first could still hold even if much of it was converted to quartz on a longer timescale. As for kaolinite, it was observed as pervasive alteration mineral with secondary electron microscopy in some of the wells (Laker, 2000; Rasmussen and Glover, 1996; Timms et al., 2012). Its better fit may be related to the alteration of muscovite to kaolinite that Rasmussen and Glover (1996) observed for the Dongara Field in the North Perth Basin (Figure 1).

Some of the well analyses lacked potassium concentrations (nd in Table 1) so that chemical reconstruction in those cases excluded the K-bearing phases muscovite and K-feldspar. This did not affect overall reconstruction, however, because these diagnostic minerals were consistently supersaturated at reconstructed reservoir temperatures and thus did not form part of any convergence strategy. Only in two wells was the sampling depth interval considered sufficient (>3000 m) to force equilibrium of the solution with K-feldspar and obtain potassium concentrations (Gingin2, Walyering). Forcing equilibrium with K-feldspar in other wells deeper than 3000m (Bootine1 and Warradong1) for which questionable potassium concentrations were available (see discussion on $\mathrm{K}-\mathrm{Cl}$ ratios above) changed only slightly the derived equilibrium temperatures (cf. Fig. 4f) but resulted in substantially lower K concentrations (cf. Table 1).

Figure 10 summarises the fluid-mineral stabilities for those reservoir samples with available potassium concentrations and formation temperatures of $90 \pm 15^{\circ} \mathrm{C}$. The activity diagram was constructed based on Gibbs free energies of formation from Holland and Powell (1998) for the mineral phases and Nordstrom and Munoz (1994) for the solute species and water, assuming equilibrium with chalcedony. Activity ratios of the samples determined with PHREEQC occupy a very narrow $\log \left(\mathrm{Na}^{+} / \mathrm{H}^{+}\right)$range in accordance with a (close-to) equilibrium position between 
kaolinite and albite. However, the majority of samples are offset from this horizontal equilibration line and fall into the muscovite rather than the kaolinite field, although equilibrium with the latter was more compelling for reconstruction for the majority of samples. This inconsistency can be accounted for in part by the wide temperature range plotted in Figure 10 given that the stability fields change their positions as a function of temperature. Besides, there are inconsistencies in the databases used for PHREEQC computation of the activities and the thermodynamic data used to calculate the temperature depended equilibrium constants underlying the stability fields. Another, more important factor contributing to the offset is the high potassium concentrations of some of the samples, expressed as a relatively low $\mathrm{Na} / \mathrm{K}$ mass ratio. As stated previously, high potassium concentrations did not constitute a flag for sample exclusion during the quality control although $\mathrm{KCl}$ is a major drilling fluid component. Those five samples falling plainly into the K-feldspar field and displaying $\mathrm{Na} / \mathrm{K}$ mass ratios $<2$ stem from the Warradong1 well (Table 1) and are the same ones that caused the 1:1 K/Cl ratio in Figure 7. Hence, the trend towards higher $\log \left(\mathrm{aK}^{+} / \mathrm{aH}^{+}\right)$and thus K-bearing phases in Figure 10 is skewed by the influence of $\mathrm{KCl}$ from drilling fluids.

There are two samples from the well Gingin1 (Gin1a and Gin1c in Table 1) where geochemical reconstruction failed. Applying the usual diagnostic phases to these two samples resulted in consistent undersaturation over the entire temperature range, up to $200^{\circ} \mathrm{C}$, which is suggestive of dilution effects (Reed and Spycher, 1984). Dilution of the ascending deep fluid with steam condensate after fluid depressurisation cannot be ruled out because the expected formation temperature is higher than the boiling point of water. However, removing water from these two samples to yield mineral saturation would require an 'undilution' factor of seven and eight, respectively which seems an implausible dilution volume. Besides, if dilution had indeed occurred its correction would lead to an even lower reservoir $\mathrm{pH}$ which is already quite low. It is more likely that the conspicuously low $\mathrm{pH}$ of these two samples (5.1 and 5.0), which is by far the lowest of the whole data pool and barely made it over the $\mathrm{pH}$ flag $(\mathrm{pH}<5)$, was contaminated, potentially from acid washing activities and caused the high degree of undersaturation that prevented the application of convergence measures.

\subsection{Scaling potential}

\subsubsection{Anhydrite}


After assessing individually each of the culled petroleum well analyses in the previously described way and reconstructing key parameters such as $\mathrm{pH}$ and in-situ silica equilibrium concentrations, saturation indices (SI) of the two potential scaling phases anhydrite and amorphous silica, $\mathrm{SiO}_{2}(\mathrm{am})$, were calculated (Table 1). Determination of a solid phase's saturation state is a key step to model its stability and evolution as a function of temperature changes, which are inevitable during geothermal fluid production. Anhydrite is less soluble than gypsum at higher temperature and was therefore the phase of choice. Note that the aforementioned pressure correction for anhydrite was applied to the modelling of saturation indices. By and large, the entirety of the North Perth Basin appears well undersaturated with anhydrite. Given its retrograde solubility, fluid production and subsequent heat extraction from any of these wells will either enhance the undersaturation further or at least counter the decrease in anhydrite solubility because of depressurisation. The wells $>3800 \mathrm{~m}$ depth are somewhat prone to potential anhydrite formation because the reservoir temperature is the highest and the detrimental effect of depressurisation on anhydrite solubility the greatest. Geothermal production from such deep and high temperature wells may cause sulphate precipitation from saturated reservoirs, depending on the overall temperature drop to counter depressurisation. However, in the Perth Basin geothermal energy usage is likely to focus on direct heat applications, like large-scale absorption air conditioning systems, for which temperatures below $100^{\circ} \mathrm{C}$ are sufficient (Wang et al., 2013). These temperature conditions are realised at depths $\leq 3000 \mathrm{~m}$. Given also the considerable investment costs of drilling deep(er) wells it appears not likely that anhydrite (or gypsum for that matter) will become a scaling issue for future low enthalpy heat mining in the Perth Basin.

\subsubsection{Silica}

With respect to amorphous silica, all samples cluster in the lower undersaturation range because of the lack of Si concentration data and consequent assumption of chalcedony saturation at the reconstructed formation temperature. Heat exchange will shift saturation indices towards amorphous silica saturation but it requires a significant temperature change before equilibrium can be reached. For example, in the case of the well sample Gingin1b which displays the highest reconstructed formation temperature and thus one of the lowest $\mathrm{SiO}_{2}(\mathrm{am})$ undersaturation of the entire data set (-0.6, Table 1) heat extraction needs to cause a temperature drop from $140^{\circ} \mathrm{C}$ to $40^{\circ} \mathrm{C}$ to reach solution saturation with amorphous silica. A change of silica saturation will also come about through flashing and steam generation, thus causing mass loss of solution and 
potential supersaturation of the fluid with respect to any secondary phase, including amorphous silica. However, flashing from $140^{\circ} \mathrm{C}$ to the boiling temperature of the formation water (assumed $100^{\circ} \mathrm{C}$ ) leads only to a steam fraction of $7.5 \%$ and a concomitant increase in solute concentrations of $8 \%$, not enough to reach amorphous silica saturation. The North Perth Basin is characterised by a moderate average geothermal gradient between 25 and $35^{\circ} \mathrm{C}$ deduced from the reconstructed reservoir temperatures such that production of formation fluid from depths shallower than $\sim 3 \mathrm{~km}$ will not entail boiling and steam development upon depressurisation. Under those circumstances, the process of pumping geothermal formation waters to the surface does not cause a change in the saturation state of the fluid with respect to silica polymorphs and the subsequent temperature drop via heat exchange cannot cause a shift from chalcedony to $\mathrm{SiO}_{2}(\mathrm{am})$ saturation. Although flashing depends on the salinity and gas content in the formation and will therefore vary from reservoir to reservoir it is unlikely to remove enough water to cause silica saturation.

\subsubsection{Calcite}

\subsubsection{Importance of the $\mathrm{pCO}_{2}$}

By far the most notorious scaling phase in oilfield as well as geothermal production from sedimentary basins is, however, calcite (Arnórsson, 1989; Benoit, 1989; Dalas and Koutsoukos, 1990; Oddo and Tomson, 1989; Pátzay et al., 2003; Stáhl et al., 2000; Vetter and Farone, 1987; Vetter et al., 1987). Predicting, quantifying and preventing the carbonate scaling problems that may occur in wells and surface equipment during fluid extraction operations is of crucial importance (Eseosa and Atubokiki, 2011; Garcia et al., 2006; Larsen et al., 2008). In order to assess the carbonate scaling risk and anticipate potential remedies or counter measures, key parameters of the clastic reservoir have to be known, such as the mole fraction of dissolved carbon dioxide and the related bubble point. Assuming equilibrium with calcite in the formation facilitates this information by readjusting the $\mathrm{pH}$ to comply with the determined total alkalinity. Figure 11 shows the deviation between measured and modelled $\mathrm{pH}$. Only very few samples fall on or close to the unity slope while over $90 \%$ of the measured $\mathrm{pH}$ display either loss of $\mathrm{CO}_{2}$ during sampling and/or unaccounted acetate alkalinity. Solution reconstruction not only readjusts potentially flawed $\mathrm{pH}$ measurements but also yields reservoir $\mathrm{CO}_{2}$ partial pressures $\left(\mathrm{pCO}_{2}\right)$ that are plotted versus formation temperatures in Figure 12. A linear correlation emerges which is qualitatively in agreement with literature findings. Smith and Ehrenberg (1989) 
explained the observed log $\mathrm{pCO}_{2}$ vs. temperature correlation with kinetic-independent inorganic chemical equilibrium between feldspar, clay, and carbonate minerals in the clastic (oil and gas) reservoir. The authors reported a linear fit derived from compiled sandstone reservoir data (dashed line in Fig. 12). Data included in the fit originated from the US Gulf Coast reservoir with sediments younger than 17 Ma and from the over 140 Ma old Norwegian continental shelf province. It thus stands to reason that this observation is not restricted to geography or geologic time units and is generally applicable to oil and gas reservoirs. Indeed, Bazin et al. (1997) posited that the $\mathrm{pCO}_{2}$ values (and thus correlation in Fig. 12) deduced from Smith and Ehrenberg (1989) were also applicable to the <20 Ma old Mahakam Basin in Indonesia. However, the Smith and Ehrenberg linear correlation deviates from the $\mathrm{pCO}_{2}-\mathrm{T}$ correlation found for the North Perth Basin (see figure caption). The discrepancy in the slopes of both linear least square fits can be accounted for assuming that the lower reservoir temperatures derived for the Perth Basin are over-estimated because of unachieved overall mineral-solution equilibria as discussed above. Removing the data points with formation temperatures $\leq 75^{\circ} \mathrm{C}$ from Figure 12 (not shown) changes the slope from 0.03 to 0.022 and thus improves considerably the match with the slope from Smith and Ehrenberg (1989). Concomitantly, ignoring the lower temperature data also changes the y-intercept from -3.69 to -2.76 (not shown) indicating that the $\mathrm{pCO}_{2}$ derived for the North Perth Basin are roughly twenty times lower than the values from Smith and Ehrenberg (1989). Absolute $\mathrm{pCO}_{2}$ values depend on parameters like $\mathrm{pH}$, the concentrations of carbonaterelated cations and, via activity-coefficient effects, the concentrations of other co-solutes such as methane. Additionally, the clastic formations under investigation in Smith and Ehrenberg (1989) were all mature hydrocarbon reservoirs where thermochemical disintegration and oxidation of kerogen, the prime material of crude oil and gas, during basin burial and maturation formed $\mathrm{CO}_{2}$ (Vandenbroucke and Largeau, 2007). Only parts of the North Perth Basin are regarded as recent mature hydrocarbon reservoirs (Mory and Iasky, 1996) so that the degree of kerogen oxidation and $\mathrm{CO}_{2}$ generation for the Perth Basin may have been less since deep burial which would explain the overall lower $\mathrm{CO}_{2}$ content while keeping the $\mathrm{pCO}_{2}$ - $\mathrm{T}$ trend intact. Furthermore, the type of kerogen (oxygen-rich humic vs. oxygen-poor sapropelic) and the degree of thermochemical sulphate reduction also determine the amount of available oxygen and hence the extent of carbon dioxide formation (Hunt, 1996) and may have varied from one basin to another to account for the different absolute $\mathrm{pCO}_{2}$ magnitude. 


\subsubsection{Importance of the bubble point}

The low $\mathrm{pCO}_{2}$ of the Perth Basin translates into a low bubble point. The bubble point is defined as the pressure at which the first vapour bubbles form upon either depressurisation or heating of the solution. It is thus the pressure at which the system changes from a one-phase to a two-phase system marking a crucial stage during geothermal production that requires special attention. The bubble point depends on the formation pressure (which varies during geothermal production), temperature, and on the partial molal fractions of the dissolved gases present in the formation fluid. It is thus reservoir specific. The bubble point pressure (bpp) was calculated using the equation from Satman et al. (1999):

$$
\mathrm{bpp}=\mathrm{X}_{\mathrm{CO}_{2}} \cdot \mathrm{H}_{\mathrm{k}}+\left(1-\mathrm{X}_{\left.\mathrm{CO}_{2}\right)} \cdot \mathrm{p}_{\mathrm{v}}\right.
$$

where $\mathrm{X}_{\mathrm{CO}_{2}}$ is the molar fraction of $\mathrm{CO}_{2}, \mathrm{H}_{\mathrm{k}}$ represents the Henry's law constant, and $\mathrm{p}_{\mathrm{v}}$ stands for the vapour pressure of pure water (derived from saturated steam curves) at reservoir temperature. This equation consists of summing up a first product representing the partial pressure of $\mathrm{CO}_{2}$ and a second product referring to the steam fraction of the solution. Satman et al. (1999) further provide two equations to calculate $\mathrm{H}_{\mathrm{k}}$ as a function of temperature taking the ionic strength of the solution into account. This approach is hence valid only in a $\mathrm{CO}_{2}-\mathrm{H}_{2} \mathrm{O}-$ 'brine' system; that is, assuming $\mathrm{CO}_{2}$ is the only dissolved gas in the formation waters. This may not necessarily be the case in the Perth Basin and other non-condensable gases, like $\mathrm{CH}_{4}, \mathrm{H}_{2} \mathrm{~S}$, and $\mathrm{NH}_{3}$ will reduce the boiling point of the solution and affect the bubble point pressure depending on their degree of saturation and reservoir temperature. However, $\mathrm{CO}_{2}$ is by far the most abundant of the geothermal gases, in many occasions reaching >85 vol\% (Mahon et al., 1980) such that the bubble point effect of other geothermal gases is not considered in this study. Note that this exclusion extends to those lithologies within a stratigraphy that contain natural gas. For obvious reasons, such a horizon would not suit as a hot sedimentary aquifer for geothermal production anyway and thus a potential detrimental effect of vast amounts of $\mathrm{CH}_{4}$ on the bubble point under those circumstances is not considered here. Also, it is likely that $\mathrm{H}_{2} \mathrm{~S}$ is absent in many of the petroleum wells as odour of the extracted fluid was usually recorded in the well completion reports and no positive mention of a characteristic $\mathrm{H}_{2} \mathrm{~S}$ smell was found.

Figure 13 displays the varying bubble point pressures in the North Perth Basin derived from Eq. (1). The 'fix' samples represent the 'FixAlSi' approach whereas the 'raw' data points ignore 
organic alkalinity and the pressure effect on $\mathrm{K}_{\mathrm{sp}}$. The importance of organic alkalinity is highlighted with a cross for those 'raw' well samples whose corresponding 'fix' samples reached organic alkalinity $\geq 60 \%$ of total alkalinity ('alk'). As can be seen in Figure 13, bubble points derived from the 'raw' method are consistently higher because this approach overestimates bicarbonate alkalinity and the $\mathrm{pCO}_{2}$ required to reach calcite equilibrium. Ignoring the contribution from organic alkalinity is especially detrimental as can be seen by the conspicuous deviation of the 'alk' samples from linearity leading to the largest discrepancies with the more realistic bubble points from the 'FixAlSi' technique. The 'fix' data neatly line up forming a linear slope $\left(r^{2}=0.96\right)$ because both terms in Eq. (1) display a log-linear relationship. The first term corresponds to Figure $12\left(\log \mathrm{pCO}_{2}\right.$ vs. T) whereas the second term refers to the saturated steam curve of pure water that can be satisfactorily approximated with a linear, semi-log relationship (log $\mathrm{p}_{\mathrm{v}}$ vs. T) over the temperature range found in this study (see dotted pure water vapour curve in Fig. 13). The bubble points from the 'fix' data set remain below 10 bar over the entire temperature range and are primarily influenced by the water vapour pressure.

At sub-boiling temperatures, the bubble point even remains $\leq 2$ bar, a pressure that can be readily maintained in the entire geothermal extraction cycle. Keeping the geothermal fluid under pressures higher than the bubble point during production, heat exchange and re-injection is a desired target because it will avoid phase segregation and flash scaling of carbonates. Else, during ascent of the geothermal fluid, bubbles will invariably form at the bubble point which happens at a discrete depth in the production pipe. If $\mathrm{CO}_{2}$ is the major dissolved gas, the bubble point will coincide with a rise in fluid $\mathrm{pH}$ because of $\mathrm{CO}_{2}$ degassing and decreased carbonate solubility. Given that the formation is expected to be at equilibrium with calcite, any increase of its saturation during production will evidently promote carbonate scaling. Zhang et al. (2001) analysed a carbonate scale profile from downhole logging from a North Sea oilfield well and reported considerable carbonate scale build-up over a depth range of only 800 feet (ca. 240 m) with scaling rates highest at the gas entry point and gradually declining to almost zero. Apart from scaling, another reason to avoid the fluid crossing the bubble point is the fact that geothermal exploitation from liquid-dominated low enthalpy fields often takes place with the help of a downhole pump to produce the geothermal waters. These downhole pumps are very susceptible to the presence of bubbles and accumulation of gases; for example, cavitation impairs the functioning of the pump, reduces its efficiency and leads to pump damage (Aksoy, 2007). All 
these risks can be avoided by adequately choosing the installation depth of the production pump and pressurising the well (and subsequent heat extraction and re-injection line) above the bubble point. However, a high operating pressure of the production line signifies a high backpressure on the production pump and thus translates into a shorter pump lifetime and higher energy consumption during fluid uplift. There are therefore limitations to the usefulness of keeping the producer over-pressurised. The derived bubble points from the compiled North Perth Basin wells are very moderate meaning that, under the afore-mentioned supposition of no other noncondensable gases interfering, for each sampled formation, pressurisation of the operation line from producer to injector seems feasible to avoid carbonate scaling and technical issues with the downhole pump. The lack of available gas data from the petroleum well samples precludes any further discussion related to the bubble point, such as adequate installation depth of the production pump, pumping rate, or operating pressure to dodge carbonate scaling. It is, however, noteworthy to discuss what the consequences would be if additional non-condensable gases were present which would enhance the bubble point to such (high) pressures that bubbling in the well could not be eluded.

\subsubsection{Importance of flashing}

If operating pressures cannot be kept above the bubble point, flash scaling of carbonates will occur whose extent can be approximated using literature findings. Zhang et al. (2001) carried out experiments on the kinetics of carbonate scaling and derived two kinetic expressions that, combined, enable the determination of calcite scaling thicknesses during fluid production:

$\log k_{\mathrm{p}}=0.126(\mathrm{I})^{0.5}-2400 / \mathrm{T}_{\mathrm{K}}-0.34 \mathrm{pH}+0.222$

$\mathrm{R}_{\mathrm{L}}=\mathrm{k}_{\mathrm{p}}\left(\mathrm{S}^{0.5}-1\right)^{2}$

where $k_{p}$ stands for the empirical rate constant $(\mathrm{m} / \mathrm{s})$, I represents the ionic strength $\left(\mathrm{mol} / \mathrm{kg}_{\mathrm{w}}\right)$, $T_{K}$ is the temperature in Kelvin, $R_{L}$ denotes the growth rate of calcite crystal surfaces $(\mathrm{m} / \mathrm{s})$, and $\mathrm{S}$ symbolises the saturation ratio (IAP/ $\mathrm{K}_{\mathrm{sp}}$ ), which is equivalent to $10^{\mathrm{SI}}$. The dependence of $\mathrm{k}_{\mathrm{p}}$ on the $\mathrm{Ca} / \mathrm{HCO}_{3}$ ratio is implicit in the $\mathrm{pH}$ term (Zhang and Dawe, 1998) whereas the inhibitory effect of Mg on calcite growth was included in the last term in Eq. (2) (+0.222) which varies as a function of the molar $\mathrm{Mg} / \mathrm{Ca}$ ratio (Dawe and Zhang, 1997). Experimental studies on the relationship between flow velocity and carbonate scale kinetics indicate that at flow velocities greater than $0.5 \mathrm{~m} / \mathrm{s} \mathrm{k}_{\mathrm{p}}$ stabilizes and becomes independent (Zhang and Farquhar, 2001). Based 
on these two equations, $\mathrm{R}_{\mathrm{L}}$ were calculated and then multiplied by a constant amount of time (30 days expressed in seconds) to yield calcite scaling thicknesses (CST). CST are thus defined in this study as the varying thicknesses of calcite coating expected to form on production piping during geothermal ascent after a month based on specific physicochemical properties of the respective solutions and a flow velocity of $>0.5 \mathrm{~m} / \mathrm{s}$.

The result of this approximation is presented in Figure 14, where calculated CST are plotted against the reservoir temperature. Eqs. (2-3) depend on the $\mathrm{pH}$, temperature, ionic strength, and degree of saturation of the reservoir water. Traversing the bubble point will increase $\mathrm{pH}$ and carbonate saturation to an unknown extent before precipitation occurs. It is therefore not possible to apply Eqs. (2-3) directly to the reconstructed petroleum well samples as they are considered in equilibrium with the minerals of the reservoir, including calcite. However, by assuming constant calcite supersaturation and $\mathrm{pH}$ (i.e., after $\mathrm{CO}_{2}$ degassing started but prior to calcite nucleation) CST can be derived and plotted as a function of the solution temperature (Fig. 14). Given the relationship in Eq. (2) an exponential trend emerges with anticipated CST ranging from few micrometres at relatively low supersaturation and temperature to centimetres and decimetres at higher supersaturation and temperature after one month. Total blockage of a 2” production pipe ( $\sim 5 \mathrm{~cm}$ ID) may thus occur in matters of few months from a consistently supersaturated solution under otherwise constant pH-T-I conditions. Figure 14 was generated at pH 6 and an ionic strength of 0.3 molal but changing both parameters within the range of values found in the Perth Basin would not alter the figure substantially. The fact that the degree of supersaturation together with the temperature exert such a huge impact on $\mathrm{k}_{\mathrm{p}}$ and by extension on $\mathrm{R}_{\mathrm{L}}$ and subsequently CST signifies that formation depth is a first order control on scaling kinetics. Firstly, the formation depth exerts a direct temperature effect on calcite solubility, growth kinetics and CST (Figure 14) and secondly, the $\mathrm{pCO}_{2}$ increases with increasing temperature (Figure 12) such that more $\mathrm{CO}_{2}$ will eventually degas during uplift leading to a greater amount of carbonate scaling. Temperature, and therefore depth is, however, also a key factor in geothermal exploration. As long as temperature requirements are met during geothermal production, the shallower the production well the better it is to keep CST to a minimum if flash scaling cannot be averted altogether. 
These considerations hold under the premise that Eqs. (2-3) are also applicable to geothermal systems as they were originally developed as part of an initiative to predict oilfield downhole scaling. This appears to be a reasonable supposition as the experimental conditions under which Zhang et al. (2001) derived their kinetic expressions fall well within the boundaries of conditions encountered in the North Perth Basin. While the authors used $\mathrm{NaCl}$ fluids of somewhat higher salinity ( 1 molal) their experimental temperature $\left(70\right.$ and $\left.90{ }^{\circ} \mathrm{C}\right)$ and $\mathrm{pH}(5.9-7.5)$ are similar to the formation conditions of the petroleum wells.

\subsubsection{Redox scaling}

The entire discussion on scaling revolves around the production and heat exchange sequences whereas the re-injection stage has been neglected. The reason for the omission is that the last part of the geothermal exploitation cycle requires knowledge about the chemical composition of the injection formation, which may not be the same as the production formation. In fact, if geothermal production is linked to carbon storage activities, the injection zone will likely be

located above a sealing layer that separates the deeper geothermal production formation from the next shallower permeable horizon to enable effective pressure management of the carbon storage reservoir (Buscheck et al., 2012). In general, re-injection into an aquifer other than the one from which the heat is extracted in the first place will cause changes in the redox state of the solution that cannot be addressed without data on the redox potential in the production and injection reservoirs, respectively.

Yet, these changes in the redox potential may turn out to be crucial in terms of potential scaling and substantial injectivity losses. For example, Kühn et al. (1998) studied the permeability changes related to brine injection into a clastic reservoir and concluded that reinjection of oxidised water should be avoided because it resulted in a strong permeability decrease due to creation of high amounts of colloidal iron hydroxide. On the other hand, reduction of solute sulphate by bacteria was deemed responsible for formation of iron sulphides that significantly deteriorated the injectivity of a $\mathrm{CO}_{2}$ injection well (Zettlitzer et al., 2010). As such, any change in the redox state bears the potential to create secondary (iron) phases in or around the injector. To compound this problem further, Criaud et al. (1989) observed a lack of overall redox equilibrium within an aquifer of the Paris Basin and alleged the occurrence of microenvironments with very reducing conditions to account for the presence of variable iron 
sulphide phases. This suggests that even reinjection into the same aquifer may run the risk of changing the redox state and calls for special attention and geochemical modelling when choosing the appropriate depths of and distance between the producer-injector doublet.

\section{Conclusion}

\subsection{Perth Basin overview}

A dataset of incomplete major element analyses from 148 petroleum well samples from a database compilation of the Perth Basin was analysed for its geochemical information. After applying a set of quality control criteria this pool of chemical analyses was reduced by $71 \%$ to 43 samples from 31 discreet depth intervals of 20 individual wells that are deemed to represent relatively genuine formation fluids. They are invariably $\mathrm{NaCl}$ solutions of low to medium alkalinity and an ionic strength only occasionally reaching seawater salinity ( 0.7 molal, equivalent to $41,000 \mathrm{ppm})$. The low TDS indicates the absence of extended evaporites in the North Perth Basin and the prevalence of meteoric water infiltration and circulation at depths.

The overall low ionic strength solutions underwent a forced equilibrium treatment based on a literature protocol to reconstruct in-situ reservoir temperatures and concentrations of missing elements ( $\mathrm{Si}, \mathrm{Al}, \mathrm{K})$, organic acid anions and non-carbonate alkalinity, and $\mathrm{pH}$. The petroleum well samples are modelled to be in equilibrium with chalcedony (and kaolinite, albite, and paragonite) in the reservoir which yielded better convergence than using quartz instead. The derived formation temperatures correspond to geothermal gradients in the majority of cases between $25-35^{\circ} \mathrm{C}$, in accord with literature findings. The wells are modelled to be undersaturated with respect to amorphous silica and anhydrite and saturated with calcite in the formation. This model is consistent with petrographic sediment core descriptions that mention calcite as ubiquitous carbonate phase whereas anhydrite and amorphous silica are absent (Laker, 2000; Owad-Jones and Ellis, 2000; Rasmussen and Glover, 1996; Timms et al., 2012).

\section{$5.2 \quad$ Scaling}

Geothermal production from any of these North Perth Basin wells will change the saturation state of these phases. However, sulphates and carbonates show retrograde solubilities meaning that the temperature loss experienced will maintain the phases in solution rather than prompt their precipitation. Although depressurisation will lead to reduced anhydrite solubility, it is found to be sufficiently undersaturated in the reservoir at depth $\sim<3800 \mathrm{~m}$. Given the solubility 
enhancing temperature decrease experienced during heat exchange, its precipitation is therefore unlikely. For calcite, scaling predictions depend in how far bubbling and phase segregation can be suppressed. Degassing of $\mathrm{CO}_{2}$ during fluid ascent and depressurisation will lead to $\mathrm{pH}$ and calcite solubility changes resulting in flash scaling. And cavitation may also disturb the system sufficiently to start calcite nucleation. Literature findings provide a kinetics expression for calcite growth under specific pH-T-I-SI conditions and based on this expression calcite scaling thicknesses are calculated and shown to be very sensitive to the degree of supersaturation and temperature. It means that if bubbling cannot be avoided because of inherent high bubble point pressures, the production depth should be as shallow as feasible to keep calcite scaling to a minimum. For the six different stratigraphies of the North Perth Basin, some of which may serve as potential hot sedimentary aquifers from which to draw geothermal waters, the calculated bubble points are low, however, such that pressurisation of the entire production and re-injection line seems viable.

As for amorphous silica, under the assumption of in-situ equilibrium with chalcedony in the formation, the solutions remain sufficiently undersaturated after uplift, partial depressurisation, and heat exchange to run the risk of amorphous silica scaling. For heat exchange to become relevant, the fluid would have to be cooled down below its economic value and boiling via depressurisation would require substantially higher reservoir temperatures than those found for the Perth Basin to result in sufficient steam generation and corresponding water mass loss from solution to concentrate solute silica to saturation.

Given that vital data on the gas compositions for the petroleum wells are lacking, all aforementioned generalised conclusions on the bubble point are uncertain. Only a systematic sampling tour of accessible, unplugged deeper wells yielding missing key parameters such as the gas composition, solute iron, dissolved organic carbon, bacterial activity, and redox potential can complement the presented preliminary geochemical picture. These shortcomings notwithstanding, this study promotes the application of valuable, readily accessible protocols from the literature to deep well samples that may otherwise appear to have little geochemical bearing because of the lack of data and the way they were generated in the first place. After data culling and treatment, insights into the geochemistry of deep clastic formations of the North 
Perth Basin that may hold the potential for geothermal exploitation as hot sedimentary aquifers can be gained.

\section{Acknowledgements}

The authors thank their colleagues from the Western Australia Geothermal Centre of Excellence for continuous support and intellectual exchange. The paper benefited from constructive criticisms from Tamie Weaver, Thráinn Fridriksson, and the associate editor Adrian Bath which are much appreciated. This project is part of an Australian Research Council (ARC) linkage project (\# LP110100597) and DWB gratefully acknowledges funding from ARC and the geothermal company GT Power.

\section{References}

Aksoy, N., 2007. Optimization of downhole pump setting depths in liquid-dominated geothermal systems: A case study on the Balcova-Narlidere field, Turkey. Geothermics 36, 436-458.

Arnórsson, S., 1989. Deposition of calcium carbonate minerals from geothermal waters theoretical considerations. Geothermics 18, 33-39.

Bazin, B., Brosse, E., Sommer, F., 1997. Chemistry of oil-field brines in relation to diagenesis of reservoirs .1. Use of mineral stability fields to reconstruct in situ water composition. Example of the Mahakam basin. Marine and Petroleum Geology 14, 481-495.

Benoit, W.R., 1989. Carbonate scaling characteristics in Dixie Valley, Nevada geothermal wellbores. Geothermics 18, 41-48.

Bjørlykke, K., Gran, K., 1994. Salinity variations in North Sea formation waters: implications for large-scale fluid movements. Marine and Petroleum Geology 11, 5-9.

Blount, C.W., Dickson, F.W., 1969. The solubility of anhydrite (CaSO4) in NaCl-H2O from 100 to $450^{\circ} \mathrm{C}$ and 1 to 1000 bars. Geochimica Et Cosmochimica Acta 33, 227-245.

Buscheck, T.A., Sun, Y., Chen, M., Hao, Y., Wolery, T.J., Bourcier, W.L., Court, B., Celia, M.A., Julio Friedmann, S., Aines, R.D., 2012. Active CO2 reservoir management for carbon storage: Analysis of operational strategies to relieve pressure buildup and improve injectivity. International Journal of Greenhouse Gas Control 6, 230-245.

Cadman, S.J., Pain, L., Vuckovic, V., 1994. Perth Basin, W.A., Australian Petroleum Accumulations Report 10. Bureau of Resource Sciences, Canberra. 
Connolly, C.A., Walter, L.M., Baadsgaard, H., Longstaffe, F.J., 1990. Origin and evolution of formation waters, Alberta Basin, Western Canada sedimentary Basin. I. Chemistry. Applied Geochemistry 5, 375-395.

Criaud, A., Fouillac, C., Marty, B., 1989. Low enthalpy geothermal fluids from the paris basin. 2-Oxidation-reduction state and consequences for the prediction of corrosion and sulfide scaling. Geothermics 18, 711-727.

Crostella, A., 1995. An evaluation of the hydrocarbon potential of the onshore northern Perth Basin. Western Australia Geological Survey, Report 43, p. 67.

Crostella, A., Backhouse, J., 2000. Geology and petroleum exploration of the central and southern Perth Basin, Western Australia. Western Australia Geological Survey, Report 57, p. 85.

Dalas, E., Koutsoukos, P.G., 1990. Calcium carbonate scale formation and prevention in a flowthrough system at various temperatures. Desalination 78, 403-416.

Davidson, W.A., 1995. Hydrogeology and groundwater resources of the Perth Region, Western Australia. Western Australia Geological Survey, Bulletin 142.

Dawe, R.A., Zhang, Y., 1997. Kinetics of calcium carbonate scaling using observations from glass micromodels. Journal of Petroleum Science and Engineering 18, 179-187.

Dethlefsen, F., Haase, C., Ebert, M., Dahmke, A., 2011. Effects of the variances of input parameters on water-mineral interactions during CO2 sequestration modeling. Energy Procedia 4, 3770-3777.

Eseosa, A., Atubokiki, A.J., 2011. Prediction and Monitoring of Oilfield Carbonate Scales Using Scale Check, Nigeria Annual International Conference and Exhibition. Society of Petroleum Engineers, Abuja, Nigeria.

Furlan, S., Chaudhuri, S., Clauer, N., Sommer, F., 1995. Geochemistry of formation waters and hydrodynamic evolution of a young and restricted sedimentary basin (Mahkam Delta Basin, Indonesia). Basin Research 7, 9-20.

Garcia, A.V., Thomsen, K., Stenby, E.H., 2006. Prediction of mineral scale formation in geothermal and oilfield operations using the Extended UNIQUAC model: Part II. Carbonatescaling minerals. Geothermics 35, 239-284.

Garrels, R.M., MacKenzie, F.T., 1972. A quantitative model for the sedimentary rock cycle. Marine Chemistry 1, 27-41. 
Giggenbach, W.F., 1981. Geothermal mineral equilibria. Geochimica Et Cosmochimica Acta 45, 393-410.

Giggenbach, W.F., 1988. Geothermal solute equilibria. Derivation of Na-K-Mg-Ca geoindicators. Geochimica Et Cosmochimica Acta 52, 2749-2765.

Goldstein, T., Aizenshtat, Z., 1994. Thermochemical sulfate reduction a review. Journal of Thermal Analysis and Calorimetry 42, 241-290.

Grubbs, F.E., Beck, G., 1972. Extension of sample sizes and percentage points for significance tests of outlying observations. Technometrics $14,847-\&$.

Gupta, H., Roy, S., 2007. Geothermal Energy: An alternative resource for the 21st century. Elsevier, Amsterdam.

Hanor, J.S., 1994. Physical and chemical controls on the composition of waters in sedimentary basins. Marine and Petroleum Geology 11, 31-45.

Hanor, J.S., 2001. Reactive transport involving rock-buffered fluids of varying salinity. Geochimica Et Cosmochimica Acta 65, 3721-3732.

Hao, O.J., Chen, J.M., Huang, L., Buglass, R.L., 1996. Sulfate reducing bacteria. Critical Reviews in Environmental Science and Technology 26, 155-187.

He, S.L., Morse, J.W., 1993. Prediction of halite, gypsum, and anhydrite solubility in natural brines under subsurface conditions. Computers \& Geosciences 19, 1-22.

Hitchon, B., Brulotte, M., 1994. Culling criteria for standard formation water analyses. Applied Geochemistry 9, 637-645.

Holland, T.J.B., Powell, R., 1998. An internally consistent thermodynamic data set for phases of petrological interest. Journal of Metamorphic Geology 16, 309-343.

Hunt, J.M., 1996. Petroleum Geochemistry and Geology, 2nd ed. Freeman, New York.

Hutcheon, I., Shevalier, M., Abercrombie, H.J., 1993. pH buffering by metastable mineral-fluid equilibria and evolution of carbon dioxide fugacity during burial diagenesis. Geochimica Et Cosmochimica Acta 57, 1017-1027.

Kharaka, Y.K., Hanor, J.S., 2003. 5.16 - Deep Fluids in the Continents: I. Sedimentary Basins, in: Holland, H.D., Turekian, K.K. (Eds.), Treatise on Geochemistry. Pergamon, Oxford, pp. 499-540. 
Kühn, M., Vernoux, J.-F., Kellner, T., Isenbeck-Schröter, M., Schulz, H.D., 1998. Onsite experimental simulation of brine injection into a clastic reservoir as applied to geothermal exploitation in Germany. Applied Geochemistry 13, 477-490.

Laker, N., 2000. Sedimentological and petrographic review of the Permo-Triassic Sandstones of the Northern Perth Basin. Australian Worldwide Exploration Limited, Perth, p. 150.

Larsen, T., Lioliou, M., Ostvold, T., Josang, L.O., Randhol, P., 2008. Kinetics of CaCO3 Scale Formation During Core Flooding, SPE International Oilfield Scale Conference. Society of Petroleum Engineers, Aberdeen, UK.

Lund, J.W., Freeston, D.H., Boyd, T.L., 2011. Direct utilization of geothermal energy 2010 worldwide review. Geothermics 40, 159-180.

Macdonald, R.W., North, N.A., 1974. The Effect of Pressure on the Solubility of CaCO3, CaF2, and SrS04 in Water. Canadian Journal of Chemistry 52, 3181-3186.

Mahon, W.A.J., McDowell, G.D., Finlayson, J.B., 1980. Carbon dioxide - its role in geothermal systems. New Zealand Journal of Science 23, 133-148.

Michael, K., Bachu, S., 2002. Origin, chemistry and flow of formation waters in the Mississippian-Jurassic sedimentary succession in the west-central part of the Alberta Basin, Canada. Marine and Petroleum Geology 19, 289-306.

Mory, A.J., Iasky, R.P., 1996. Stratigraphy and structure of the onshore northern Perth Basin, Western Australia, Western Australia Geological Survey, Report 46.

Nordstrom, D.K., Munoz, J.L., 1994. Geochemical Thermodynamics, 2nd ed. The Blackburn Press, Caldwell, New Jersey.

Oddo, J.E., Tomson, M.B., 1989. A Discussion of Calcium Carbonate Scaling Problems and Solutions With Respect to Produced Brines, SPE Annual Technical Conference and Exhibition. 1989 Copyright 1989, Society of Petroleum Engineers, Inc., San Antonio, Texas.

Osborne, C.G., Ravenscroft, P.D., McCracken, I.R., 1994. Predicted water chemistry trends in North Sea formation brines. Marine and Petroleum Geology 11, 20-23.

Owad-Jones, D.L., Ellis, G.K., 2000. Western Australia atlas of petroleum fields, Onshore Perth Basin, Petroleum Division, Department of Minerals and Energy, Western Australia, p. Volume 1.

Palandri, J.L., Reed, M.H., 2001. Reconstruction of in situ composition of sedimentary formation waters. Geochimica Et Cosmochimica Acta 65, 1741-1767. 
Pang, Z.-H., Reed, M., 1998. Theoretical Chemical Thermometry on Geothermal Waters: Problems and Methods. Geochimica Et Cosmochimica Acta 62, 1083-1091.

Parkhurst, D.L., Appelo, C.A.J., 1999. User's guide to PHREEQC (Version 2)--a computer program for speciation, batch-reaction, one-dimensional transport, and inverse geochemical calculations, U.S. Geological Survey Water-Resources Investigations Report 99-4259, p.310.

Pátzay, G., Kármán, F.H., Póta, G., 2003. Preliminary investigations of scaling and corrosion in high enthalpy geothermal wells in Hungary. Geothermics 32, 627-638.

Playford, P.E., 1976. Geology of the Perth basin, Western Australia / by P.E. Playford, A.E. Cockbain and G.H. Low. Geological Survey of Western Australia.

Rasmussen, B., Glover, J.E., 1996. Fluid evolution interpreted from diagenetic assemblages and salinity data in Permo-Triassic sandstone, northern Perth Basin, Western Australia. Journal of Sedimentary Research 66, 492-500.

Reed, M., Spycher, N., 1984. Calculation of $\mathrm{pH}$ and mineral equilibria in hydrothermal waters with application to geothermometry and studies of boiling and dilution. Geochimica Et Cosmochimica Acta 48, 1479-1492.

Satman, A., Ugur, Z., Onur, M., 1999. The effect of calcite deposition on geothermal well inflow performance. Geothermics 28, 425-444.

Smith, J.T., Ehrenberg, S.N., 1989. Correlation of carbon dioxide abundance with temperature in clastic hydrocarbon reservoirs: relationship to inorganic chemical equilibrium. Marine and Petroleum Geology 6, 129-135.

Stáhl, G., Pátzay, G., Weiser, L., Kálmán, E., 2000. Study of calcite scaling and corrosion processes in geothermal systems. Geothermics 29, 105-119.

Stueber, A.M., Walter, L.M., 1991. Origin and chemical evolution of formation waters from Silurian-Devonian strata in the Illinois basin, USA. Geochimica Et Cosmochimica Acta 55, 309-325.

Timms, N.E., Corbel, S., Olierook, H., Wilkes, P.G., Delle Piane, C., Sheldon, H.A., Alix, R., Horowitz, F.G., Wilson, M.E.J., Evans, K.A., Griffiths, C., Stütenbecker, L., Israni, S., Hamilton, P.J., Esteban, L., Cope, P., Evans, C., Pimienta, L., Dyt, C., Huang, X., Hopkins, J., Champion, D., 2012. Project 2: Perth Basin Geomodel. Western Australia Geothermal Centre of Excellence, Perth. 
Vandenbroucke, M., Largeau, C., 2007. Kerogen origin, evolution and structure. Organic Geochemistry 38, 719-833.

Vetter, O.J., Farone, W.A., 1987. Calcium Carbonate Scale in Oilfield Operations, SPE Annual Technical Conference and Exhibition. 1987 Copyright 1987, Society of Petroleum Engineers, Dallas, Texas.

Vetter, O.J., Farone, W.A., Veith, E., Lankford, S., 1987. Calcium Carbonate Scale Considerations: A Practical Approach, SPE Production Technology Symposium. 1987 Copyright 1987 Society of Petroleum Engineers, Inc., Lubbock, Texas.

Wang, X., Bierwirth, A., Christ, A., Whittaker, P., Regenauer-Lieb, K., Chua, H.T., 2013. Application of geothermal absorption air-conditioning system: A case study. Applied Thermal Engineering 50, 71-80.

Willey, J.D., 1974. The effect of pressure on the solubility of amorphous silica in seawater at $0^{\circ} \mathrm{C}$. Marine Chemistry 2, 239-250.

Yardley, B., Bennett, A., Banks, D., 2003. Controls on the chemical composition of crustal brines. Journal of Geochemical Exploration 78-79, 133-135.

Zettlitzer, M., Moeller, F., Morozova, D., Lokay, P., Würdemann, H., 2010. Re-establishment of the proper injectivity of the CO2-injection well Ktzi 201 in Ketzin, Germany. International Journal of Greenhouse Gas Control 4, 952-959.

Zhang, Y., Dawe, R., 1998. The kinetics of calcite precipitation from a high salinity water. Applied Geochemistry 13, 177-184.

Zhang, Y., Farquhar, R., 2001. Laboratory Determination of Calcium Carbonate Scaling Rates for Oilfield Wellbore Environments, International Symposium on Oilfield Scale. Copyright 2001, Society of Petroleum Engineers Inc., Aberdeen, United Kingdom.

Zhang, Y., Shaw, H., Farquhar, R., Dawe, R., 2001. The kinetics of carbonate scalingapplication for the prediction of downhole carbonate scaling. Journal of Petroleum Science and Engineering 29, 85-95.

\section{Figure captions}

Figure 1. Locality maps of the Perth Basin, featuring (a) tectonic structures and cities and (b) the locations of the onshore petroleum fields and wells. The yellow hatched frame in (a) indicates 
the borders of (b) and delimits the North Perth Basin (brown rectangle). The large joint red and green patches designate the Dongara gas and oil field, respectively. The small upper green field describes the Mount Horner oil field, the red patch close to the centre marks the Yardarino gas field, and the lower red patch stands for the Mondara gas field. The sampled wells are coloured yellow. Maps adapted after Owad-Jones and Ellis (2000).

Figure 2. Stratigraphy of the Perth Basin including hydrocarbon localities and petroleum well names (modified after Cadman et al., 1994).

Figure 3. Correlation between the solubility product of calcite $\left(\mathrm{K}_{\mathrm{sp}}\right)$ and applied pressure at $1^{\circ} \mathrm{C}$ and 23 to $25^{\circ} \mathrm{C}$, respectively. Original tabulated data stem from McDonald and North (1974) and are recast in logarithmic form and recalculated to pressures in bar. Linear least square fits for both temperatures yield a similar slope. The grey rectangular indicates the expected formation pressure range in this study, based on the known sampling depth interval and assuming hydrostatic pressure only.

Figure 4. Reconstruction of in-situ formation water compositions illustrated for one petroleum well (Warr1d, Table 1). (a) Fixing the silica and aluminium concentration with quartz and kaolinite, respectively results in saturation lines that do not seem to converge at temperatures $\left(\sim 100^{\circ} \mathrm{C}\right)$ expected at formation depth. (b) Replacing (75\%) carbonate alkalinity with acetate alkalinity yields convergence of calcite and paragonite but excludes albite. (c) Fixing the silica and aluminium concentration with chalcedony and kaolinite, respectively results in saturation lines that do not seem to converge at temperatures $\left(\sim 100^{\circ} \mathrm{C}\right)$ expected at formation depth (d) Replacing (75\%) carbonate alkalinity with acetate alkalinity yields convergence of calcite, paragonite, and albite. (e) Plot of the saturation lines after inserting the $\mathrm{Si}$ and $\mathrm{Al}$ concentration derived from (d) and removing the forced equilibrium with chalcedony and kaolinite. (f) Same plot as (e) after additionally forcing equilibrium with K-Feldspar in (c) and (d); illite joins equilibrium, too.

Figure 5 Piper diagram of the 43 petroleum well samples remaining after data culling. The samples from the well Gingin1 are crossed out to distinguish them from the bulk of samples (open squares). 
Figure 6. The content of total dissolved solids (TDS) and corresponding ionic strength of the reservoir waters versus the sampling depth. The samples have been grouped according to the stratigraphy they belong to.

Figure 7. Major cation concentrations plotted against the chloride concentration. The solid line indicates a 1:1 ratio for $\mathrm{Na}$ and $\mathrm{K}(\mathrm{NaCl}, \mathrm{KCl})$ and a 1:2 ratio for $\mathrm{Mg}$ and $\mathrm{Ca}\left(\mathrm{MgCl}_{2}, \mathrm{CaCl}_{2}\right)$, respectively whereas the dashed line represents the constant ion ratio in seawater, called seawater dilution line (SWDL). The samples from the well Gingin1 are crossed out to distinguish them from the bulk of samples (open squares).

Figure 8. Lack of overall equilibrium of secondary phases because of shallow sampling depth and low formation temperature. (a) Fixing the silica and aluminium concentration with chalcedony and kaolinite, respectively results in saturation lines for Allanooka1 that do not converge at temperatures $\left(\sim 45^{\circ} \mathrm{C}\right)$ expected at the shallow sampling depth of $860 \mathrm{~m}$. (b) Adjusting the acetate alkalinity to attain equilibrium with calcite and also albite yields a reservoir temperature of $59^{\circ} \mathrm{C}$, corresponding to a dubious geothermal gradient of $45^{\circ} \mathrm{C} / \mathrm{km}$.

Figure 9. Equilibrium with chalcedony rather than quartz even at higher temperature. (a) Fixing the silica and aluminium concentration with quartz and kaolinite, respectively results in saturation lines for the well Bootine1 that do not seem to converge all at temperatures $\left(\sim 100^{\circ} \mathrm{C}\right)$ expected at formation depths. (b) Replacing chalcedony with quartz as equilibrium phase while leaving all other parameters intact results in a much better convergence without the need to add $\mathrm{CO}_{2}$ back to solution. (c) Plot of the saturation lines after inserting the Si and Al concentration derived from (b) and removing the forced equilibrium with chalcedony and kaolinite.

Figure 10. Activity diagram constructed at $90^{\circ} \mathrm{C}$ for the system $\mathrm{Na}_{2} \mathrm{O}-\mathrm{K}_{2} \mathrm{O}-\mathrm{Al}_{2} \mathrm{O}_{3}-\mathrm{SiO}_{2}-\mathrm{HCl}-$ $\mathrm{H}_{2} \mathrm{O}$. Shown are $\log \left(\mathrm{aNa}^{+} / \mathrm{aH}^{+}\right)$vs. $\log \left(\mathrm{aK}^{+} / \mathrm{aH}^{+}\right)$of well samples with formation temperatures between 75 and $105^{\circ} \mathrm{C}$. Equilibration with chalcedony is assumed. The legend refers to the $\mathrm{Na} / \mathrm{K}$ solute mass ratio.

Figure 11. Measured versus modelled $\mathrm{pH}$. Most samples lie below the unity line indicating either loss of $\mathrm{CO}_{2}$ upon depressurisation and/or unaccounted organic alkalinity. 
Figure 12. Correlation between the $\mathrm{CO}_{2}$ partial pressure $\left(\mathrm{pCO}_{2}\right)$ and the formation temperature. The solid line represents a linear least square fit $\left(\log \mathrm{pCO}_{2}=0.030 \mathrm{~T}-3.69 ; \mathrm{r}^{2}=0.68\right)$ through the selected petroleum well data. The dashed line stands for a linear least square fit $\left(\log \mathrm{pCO}_{2}=\right.$ $\left.0.02 \mathrm{~T}-1.45 ; \mathrm{r}^{2}=0.69\right)$ on Norwegian Continental Shelf samples sourced from Smith and Ehrenberg (1989).

Figure 13. Variation of the bubble point pressure for the $\mathrm{CO}_{2}-\mathrm{H}_{2} \mathrm{O}$-brine system as a function of the formation temperature (a) assuming equilibrium with calcite in the formation but without taking into account the pressure effect on the calcite solubility at depth and ignoring the contribution of acetic acid (=proxy for organic ligands) to the total alkalinity ('raw') and (b) using the 'FixAlSi' method, i.e., taking the afore-mentioned shortcomings into account and assuming equilibrium with specific secondary phases including calcite in the formation ('fix'). Those 'raw' samples that turned out to exhibit a contribution from acetate to total alkalinity $\geq 60 \%$ have been marked with a cross ('alk'). The dotted slope represents the semi-log saturated steam curve of pure water.

Figure 14. Calcite scaling thickness (CST) after 30 days of crystal growth as a function of formation temperature and degree of calcite supersaturation $(0.5,0.75,1.0)$ calculated with Eqs. (2-3) at $\mathrm{pH} 6$ and ionic strength of $0.3 \mathrm{~mol} / \mathrm{kg}$. 


\begin{tabular}{|c|c|c|c|c|c|c|c|c|c|c|c|c|c|c|c|c|c|c|c|c|}
\hline \multirow[t]{2}{*}{ well name } & \multirow[t]{2}{*}{ stratigraphy } & \multirow{2}{*}{$\begin{array}{c}\text { depth } \\
\mathrm{m}\end{array}$} & \multirow{2}{*}{$\begin{array}{c}\mathrm{T} \text { fix }{ }^{\mathrm{a}} \\
{ }^{\circ} \mathrm{C} \\
\end{array}$} & \multirow{2}{*}{$\begin{array}{c}\text { GeoGrad }^{\mathrm{b}} \\
{ }^{\circ} \mathrm{C} / \mathrm{km} \\
\end{array}$} & $\mathrm{Na}$ & $\mathrm{K}$ & $\mathrm{Ca}$ & $\mathrm{Mg}$ & $\mathrm{Cl}$ & $\mathrm{HCO}_{3}$ & $\mathrm{SO}_{4}$ & $\mathrm{SiO}_{2}{ }^{\mathrm{c}}$ & TDS & \multirow{2}{*}{$\begin{array}{r}\mathrm{Al}^{\mathrm{c}} \\
\mu \mathrm{g} / \mathrm{L} \\
\end{array}$} & $\mathrm{TA}^{\mathrm{d}}$ & $\mathrm{CA}^{\mathrm{d}}$ & $\mathrm{pH} \mathrm{lab}^{\mathrm{e}}$ & $\mathrm{pH}$ fix ${ }^{\mathrm{e}}$ & \multirow[t]{2}{*}{ SI Anhy } & \multirow[t]{2}{*}{$\mathrm{SI} \mathrm{SiO}_{2}(\mathrm{a})$} \\
\hline & & & & & \multicolumn{9}{|c|}{$\mathrm{mg} / \mathrm{L}$} & & \multicolumn{2}{|c|}{$\mathrm{meq} / \mathrm{L}$} & \multicolumn{2}{|c|}{ at $25^{\circ} \mathrm{C}$} & & \\
\hline Dongara1 & Irwin Coal & 1762 & 70 & 28 & 2490 & nd & 220 & 8 & 3360 & 840 & 563 & 42 & 7910 & 5 & 13.9 & 4.2 & 8.0 & 6.8 & -1.3 & -0.8 \\
\hline Dongara4a & Irwin Coal & 1719 & 69 & 29 & 3150 & nd & 215 & 46 & 5090 & 930 & 400 & 39 & 9520 & 5 & 15.3 & 4.6 & 7.8 & 6.8 & -1.5 & -0.8 \\
\hline Dongara4b & Irwin Coal & 1719 & 69 & 29 & 3590 & nd & 240 & 46 & 5604 & 869 & 32 & 40 & 11450 & 4 & 14.4 & 5.8 & 8.0 & 6.7 & -2.6 & -0.8 \\
\hline Dongara5 & Irwin Coal & 1537 & 76 & 36 & 1710 & nd & 112 & 15 & 2410 & 439 & 288 & 53 & 4700 & 6 & 7.2 & 6.5 & 6.8 & 6.8 & -1.7 & -0.8 \\
\hline Mount Horner1c & Irwin Coal & 1521 & 70 & 33 & 1740 & 92 & 78 & 21 & 2390 & 448 & 421 & 42 & 4900 & 6 & 7.4 & 7.4 & 7.8 & 7.0 & -1.5 & -0.8 \\
\hline Woolmulla1a & Irwin Coal & 2752 & 84 & 23 & 9540 & 835 & 506 & 102 & 14400 & 2700 & 937 & 55 & 29134 & 3 & 44.3 & 17.7 & 6.8 & 5.9 & -0.7 & -0.7 \\
\hline Woolmulla1b & Irwin Coal & 2752 & 82 & 23 & 10400 & 887 & 658 & 105 & 16380 & 2420 & 718 & 54 & 31741 & 2 & 39.7 & 15.9 & 6.7 & 5.9 & -0.7 & -0.7 \\
\hline Mount Horner1a & Carynginia & 1484 & 70 & 34 & 2100 & 87 & 119 & 44 & 3120 & 430 & 391 & 44 & 5950 & 6 & 7.1 & 6.0 & 7.1 & 6.9 & -1.4 & -0.8 \\
\hline Mount Horner1d & Carynginia & 1496 & 75 & 37 & 1800 & 92 & 102 & 21 & 2550 & 448 & 389 & 52 & 5010 & 5 & 7.4 & 7.4 & 8.1 & 6.8 & -1.4 & -0.8 \\
\hline Mount Horner1e & Carynginia & 1484 & 75 & 37 & 2060 & 87 & 141 & 39 & 3100 & 403 & 384 & 51 & 5890 & 5 & 6.6 & 6.6 & 7.5 & 6.7 & -1.4 & -0.8 \\
\hline Warradong1a & Carynginia & 3379 & 105 & 25 & 2850 & $1730 / 40$ & 72 & 5 & 4913 & 2367 & 64 & 92 & 12000 & 12 & 38.8 & 38.8 & 6.9 & 6.0 & -2.2 & -0.7 \\
\hline Mount Horner1b & Wagina & 1573 & 69 & 31 & 1450 & 62 & 118 & 21 & 2130 & 268 & 372 & 42 & 4160 & 7 & 4.4 & 4.0 & 7.1 & 7.1 & -1.3 & -0.8 \\
\hline Warradong1b & Wagina & 3285 & 96 & 23 & 2700 & $1430 / 30$ & 61 & 3 & 4572 & 2050 & 45 & 79 & 10860 & 10 & 33.6 & 33.6 & 6.8 & 6.3 & -2.4 & -0.7 \\
\hline Yardarino1a & Wagina & 2304 & 78 & 25 & 6600 & 442 & 564 & 67 & 10700 & 1500 & 250 & 48 & 19300 & 3 & 24.6 & 7.4 & 7.3 & 6.3 & -1.2 & -0.8 \\
\hline Yardarino1b & Wagina & 2299 & 77 & 25 & 5560 & 423 & 546 & 56 & 7100 & 3590 & 1210 & 49 & 18200 & 3 & 58.9 & 5.9 & 7.2 & 6.4 & -0.5 & -0.8 \\
\hline Allanooka1 & Basal Trias & 860 & 59 & 45 & 1450 & 71 & 165 & 48 & 2305 & 311 & 332 & 35 & 4570 & 3 & 5.1 & 2.6 & 7.5 & 7.2 & -1.4 & -0.8 \\
\hline Dongara3 & Basal Trias & 1601 & 72 & 32 & 1950 & nd & 120 & 39 & 2627 & 2150 & 800 & 44 & 7800 & 5 & 35.3 & 8.1 & 7.4 & 6.8 & -1.3 & -0.8 \\
\hline Eurangoa1 & Basal Trias & 1693 & 95 & 44 & 1480 & nd & 192 & 44 & 2170 & 368 & 500 & 79 & 3550 & 13 & 6.0 & 4.8 & 6.5 & 6.4 & -1.3 & -0.7 \\
\hline Mount Horner2b & Basal Trias & 1555 & 65 & 29 & 1350 & 85 & 127 & 25 & 2040 & 268 & 354 & 23 & 4190 & 2 & 4.4 & 4.4 & 7.6 & 7.0 & -1.3 & -1.0 \\
\hline Warradong1c & Basal Trias & 3178 & 96 & 24 & 3125 & 1875 & 135 & 13 & 6284 & 1208 & 100 & 73 & 12740 & 9 & 19.9 & 17.9 & 7.6 & 6.2 & -1.8 & -0.7 \\
\hline Warradong1d & Basal Trias & 3178 & 98 & 25 & 3175 & $3275 / 36$ & 360 & 22 & 7597 & 1891 & 100 & 70 & 16420 & 11 & 31.0 & 7.8 & 6.7 & 6.1 & -1.5 & -0.7 \\
\hline Warradong1e & Basal Trias & 3178 & 99 & 25 & 2825 & 1525 & 125 & 10 & 5396 & 1391 & 76 & 81 & 11348 & 9 & 23.1 & 23.1 & 8.1 & 6.1 & -1.9 & -0.7 \\
\hline Yardarino2a & Basal Trias & 2335 & 75 & 24 & 8680 & 1120 & 1310 & 131 & 15900 & 1810 & 180 & 42 & 27600 & 2 & 29.7 & 4.5 & 6.9 & 6.2 & -1.1 & -0.8 \\
\hline Yardarino2b & Basal Trias & 2335 & 80 & 26 & 11550 & 231 & 2370 & 201 & 21900 & 1340 & 157 & 50 & 36800 & 2 & 22.0 & 5.5 & 6.5 & 5.9 & -1.0 & -0.7 \\
\hline Yardarino4a & Basal Trias & 2330 & 90 & 30 & 8370 & 355 & 921 & 143 & 15100 & 515 & 4 & 59 & 25420 & 4 & 8.4 & 8.4 & 6.3 & 5.8 & -2.9 & -0.8 \\
\hline Yardarino4b & Basal Trias & 2330 & 89 & 30 & 8350 & 355 & 938 & 143 & 15000 & 762 & 3 & 65 & 25460 & 2 & 12.5 & 12.5 & 6.4 & 5.7 & -3.0 & -0.7 \\
\hline Yardarino4c & Basal Trias & 2330 & 89 & 30 & 8280 & 355 & 870 & 158 & 14750 & 625 & 5 & 65 & 25000 & 3 & 10.2 & 10.2 & 6.4 & 5.8 & -2.8 & -0.7 \\
\hline
\end{tabular}




\begin{tabular}{|c|c|c|c|c|c|c|c|c|c|c|c|c|c|c|c|c|c|c|c|c|}
\hline Bootine1 & Cattamarra & 3747 & 125 & 28 & 4100 & $5700 / \mathbf{1 1 9}$ & 368 & 128 & 11500 & 1461 & 680 & 120 & 23940 & 14 & 24.3 & 24.3 & 8.2 & 5.4 & -0.7 & -0.6 \\
\hline Gingin1a & Cattamarra & 3814 & nd & nd & 3470 & 118 & 2090 & 1030 & 11800 & 299 & 260 & 59 & 21000 & nd & 4.9 & nd & 5.1 & nd & nd & nd \\
\hline Gingin1b & Cattamarra & 3814 & 140 & 31 & 2907 & 94 & 504 & 306 & 5370 & 964 & 563 & 154 & 10600 & 24 & 15.8 & 15.8 & 7.4 & 5.3 & -0.6 & -0.6 \\
\hline Gingin1c & Cattamarra & 3865 & nd & nd & 3288 & 100 & 2100 & 209 & 8700 & 207 & 882 & 91 & 15800 & nd & 3.4 & nd & 5.0 & nd & nd & nd \\
\hline Gingin1d & Cattamarra & 3865 & 121 & 26 & 3580 & 82 & 2690 & 485 & 11200 & 232 & 618 & 103 & 19300 & 19 & 3.8 & 3.8 & 6.0 & 5.7 & -0.3 & -0.7 \\
\hline Gingin1e & Cattamarra & 3865 & 111 & 24 & 4360 & 90 & 3260 & 294 & 12900 & 110 & 614 & 95 & 22100 & 10 & 1.8 & 1.8 & 5.8 & 5.8 & -0.1 & -0.6 \\
\hline Gingin1f & Cattamarra & 4151 & 131 & 27 & 2340 & 82 & 136 & 26 & 2240 & 2650 & 299 & 134 & 6560 & 20 & 43.5 & 43.5 & 7.2 & 5.4 & -0.9 & -0.6 \\
\hline Gingin2a & Cattamarra & 3837 & 104 & 22 & 6700 & 81 & 485 & 147 & 10400 & 1090 & 891 & 82 & 19600 & 7 & 17.9 & 17.9 & 6.8 & 5.7 & -0.7 & -0.7 \\
\hline Gingin2b & Cattamarra & 4233 & 100 & 19 & 6440 & 70 & 526 & 74 & 10100 & 1020 & 737 & 81 & 18000 & 5 & 16.7 & 16.7 & 6.8 & 5.8 & -0.7 & -0.7 \\
\hline Mount Horner2a & Cattamarra & 1208 & 69 & 41 & 1550 & 85 & 143 & 47 & 2300 & 537 & 336 & 39 & 4790 & 9 & 8.8 & 3.1 & 7.6 & 7.2 & -1.4 & -0.8 \\
\hline Mount Horner4 & Cattamarra & 1323 & 63 & 33 & 1529 & nd & 90 & 40 & 2439 & 308 & 33 & 36 & 4445 & 6 & 5.1 & 4.1 & 7.9 & 7.2 & -2.5 & -0.8 \\
\hline Walyering1 & Cattamarra & 3270 & 103 & 25 & 4880 & 61 & 299 & 29 & 7550 & 974 & 32 & 87 & 14800 & 7 & 80.0 & 80.0 & 6.9 & 5.8 & -2.0 & -0.7 \\
\hline Gage Roads1 & Gage Sdst & 1779 & 73 & 30 & 12480 & nd & 1676 & 189 & 22000 & 480 & 702 & 39 & 38200 & 2 & 7.9 & 5.5 & 6.7 & 6.1 & -0.9 & -0.8 \\
\hline
\end{tabular}

Table 1. Chemical compositions of the culled petroleum well samples ordered according to their stratigraphy. The letter behind the well name \& number distinguishes different samples from the same well. The last two columns are the saturation indices (SI) of anhydrite and amorphous silica. The bold numbers in the K column are reconstructed potassium concentrations from some deep wells; nd = not determined.

${ }^{\mathrm{a}} \mathrm{T}$ fix is the reconstructed formation temperature

${ }^{\mathrm{b}}$ GeoGrad is the derived geothermal gradient based on the sampling depth and a surface temperature of $20^{\circ} \mathrm{C}$

${ }^{\mathrm{c}}$ Solute silica and $\mathrm{Al}$ concentrations after reconstruction

${ }^{\mathrm{d}}$ TA and CA are total and carbonate alkalinity

${ }^{\mathrm{e}} \mathrm{pH}$ lab is the measured $\mathrm{pH}$ after sampling (in the field or lab) whereas $\mathrm{pH}$ fix is the reconstructed $\mathrm{pH}$ 

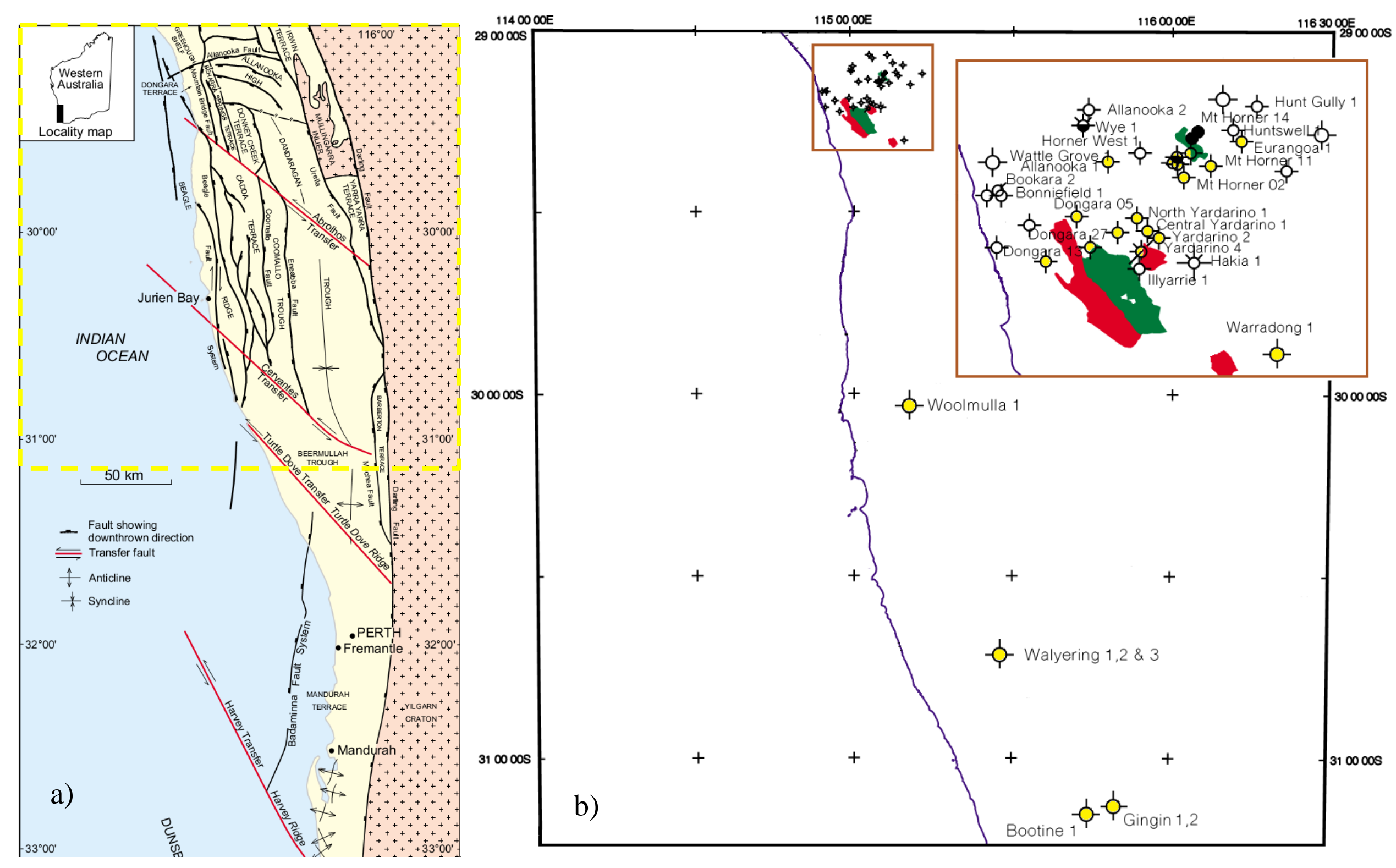

Figure 1 


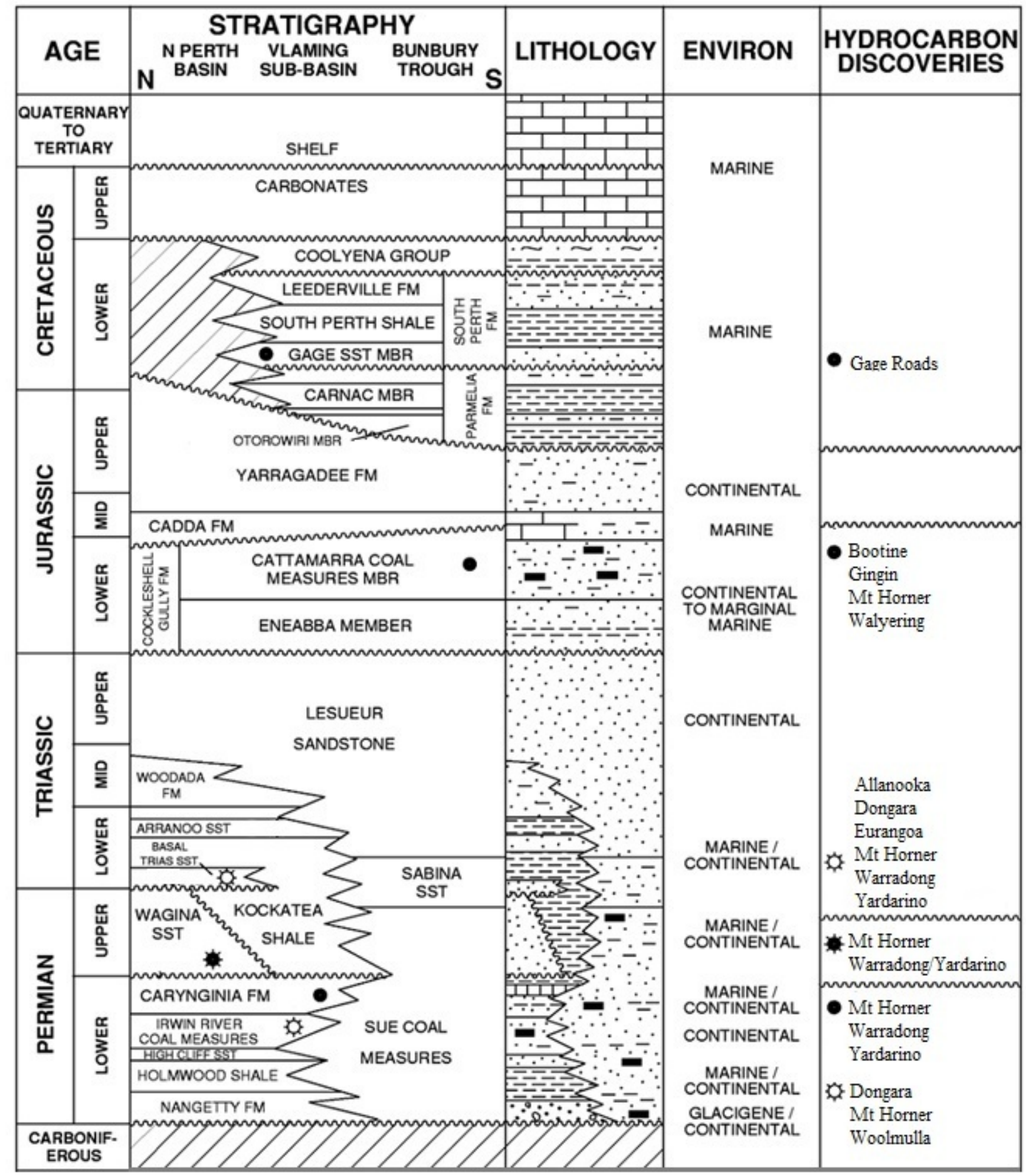

Figure 2 


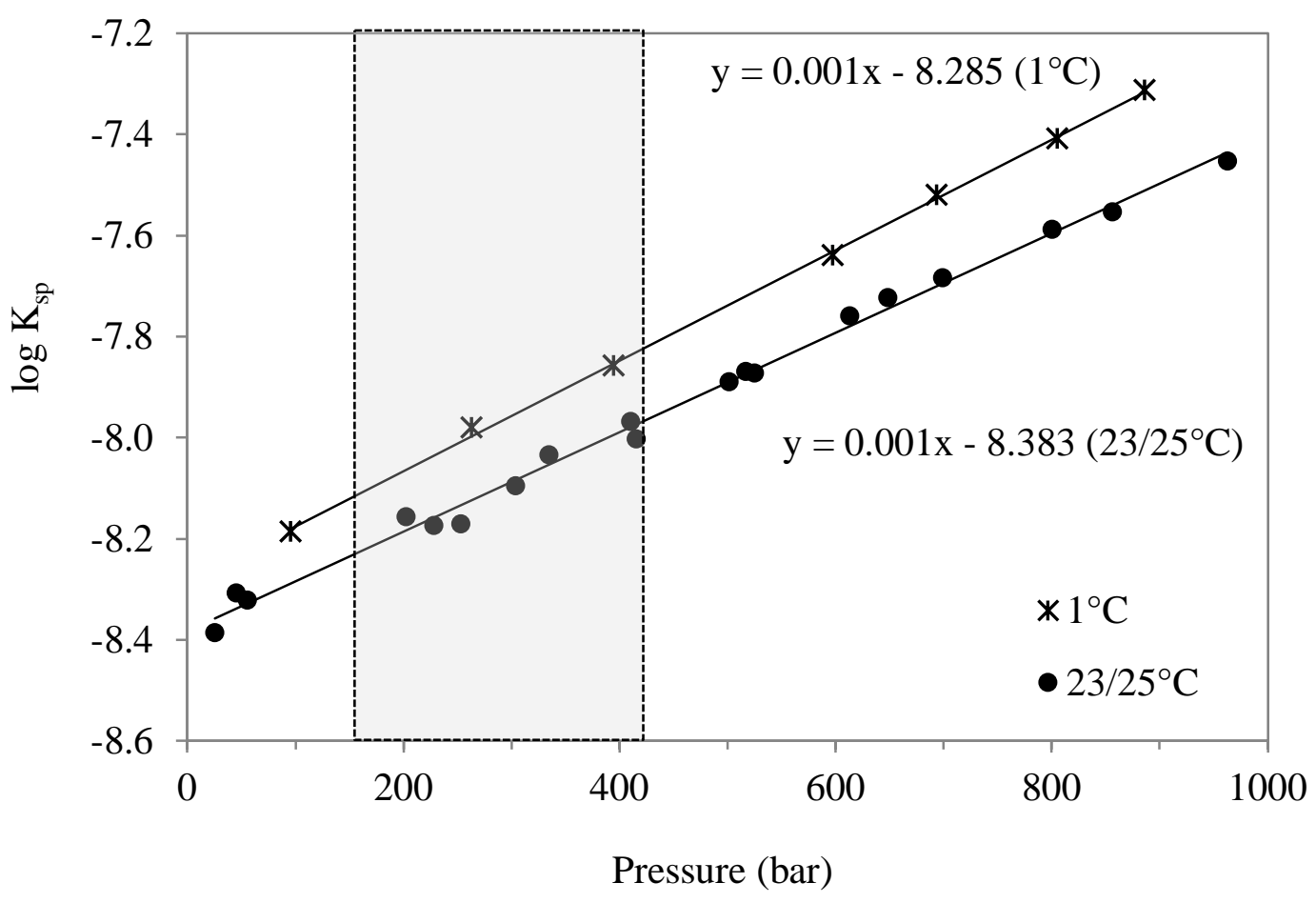

Figure 3 
(a) FixAlSi, Qz\&Kaol

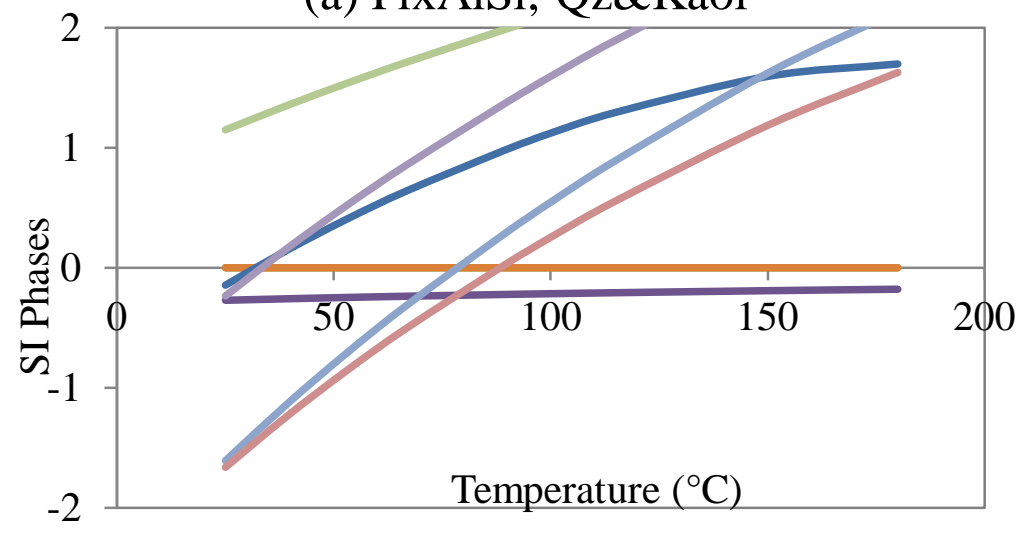

(c) FixAlSi, Chal\&Kaol

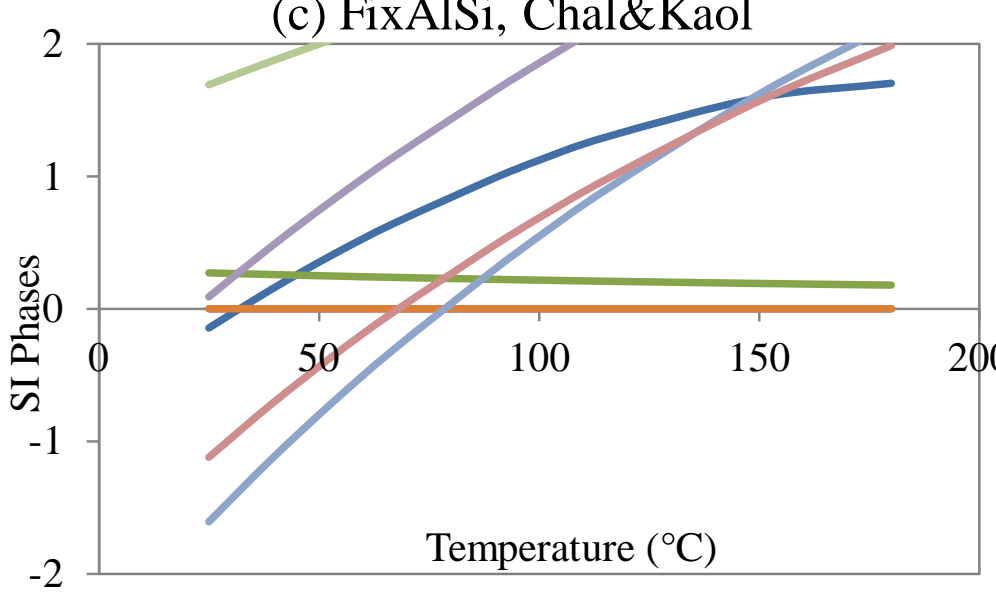

(e) Chal\&Kaol, alk

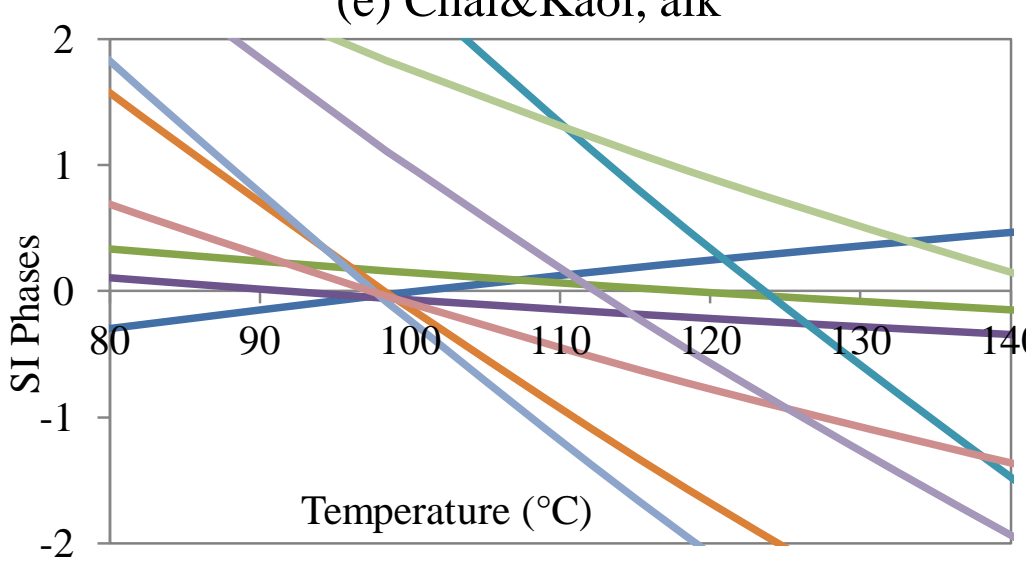

(b) FixAlSi, Qz\&Kaol, alk

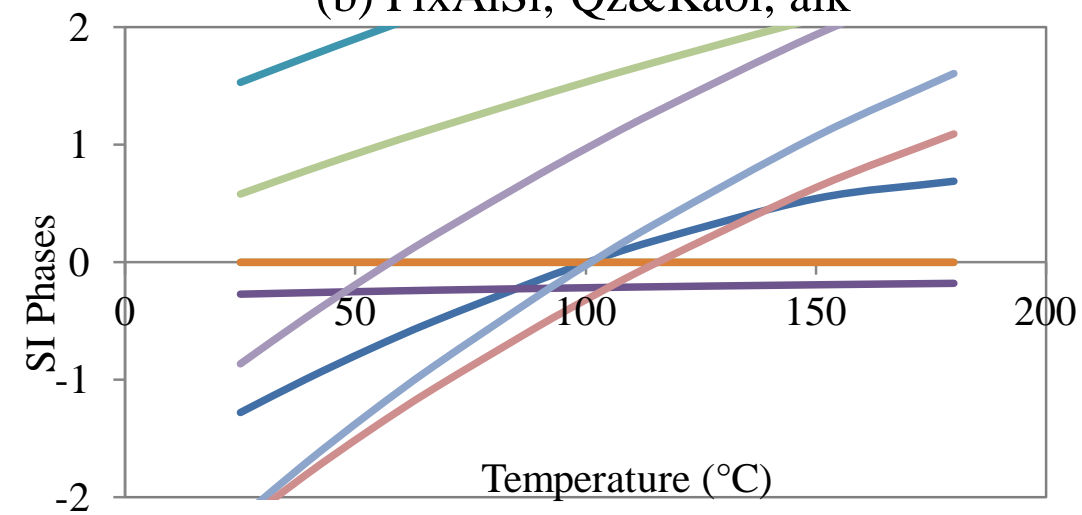

(d) FixAlSi, Chal\&Kaol, alk

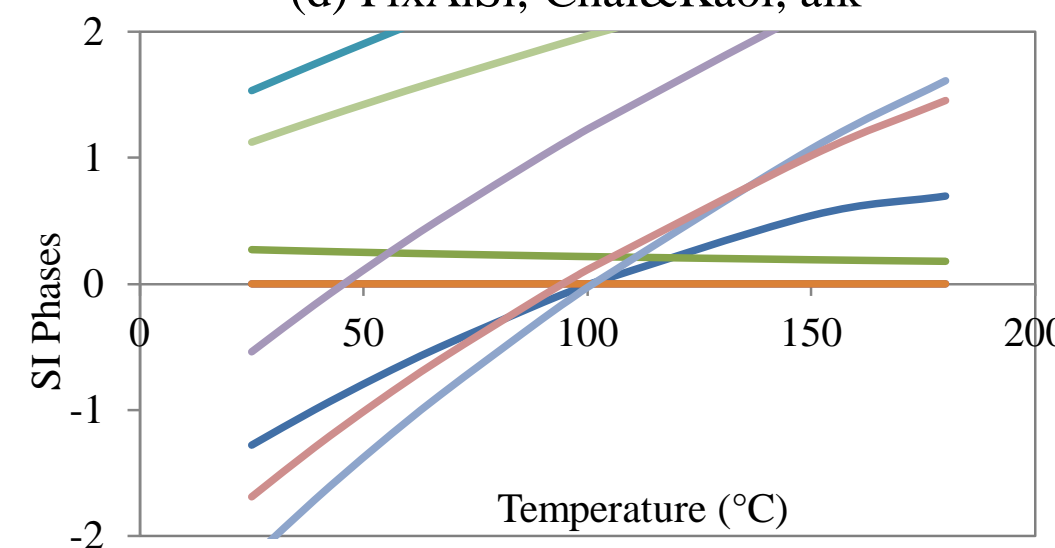

—si Quartz

—si_Chalcedony

— si Muscovite

— si Kaolinite

- si_Calcite

—si_Paragonite

— si_Albite

— si_K-feldspar

—si_Illite

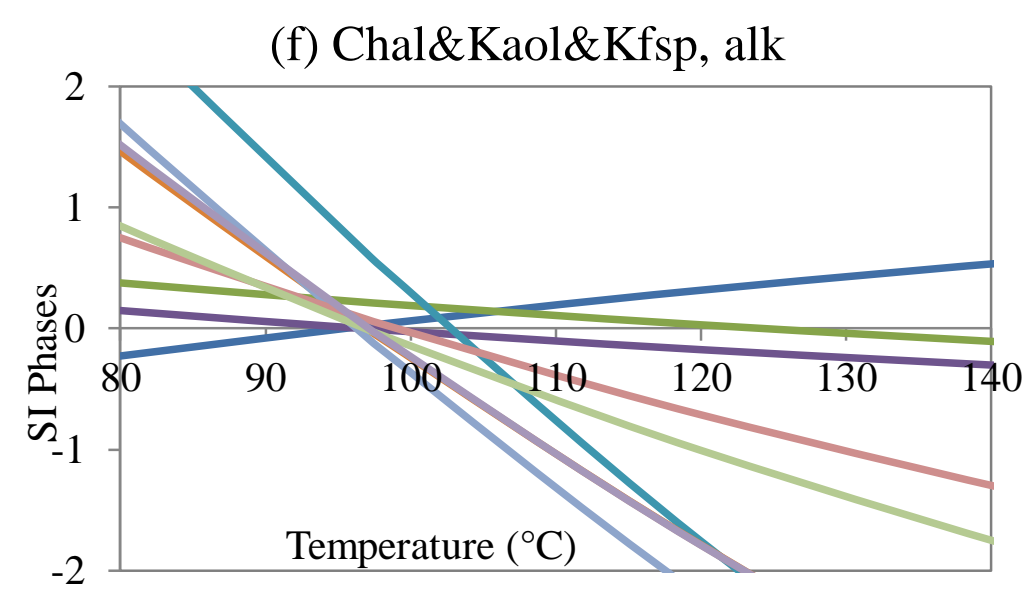




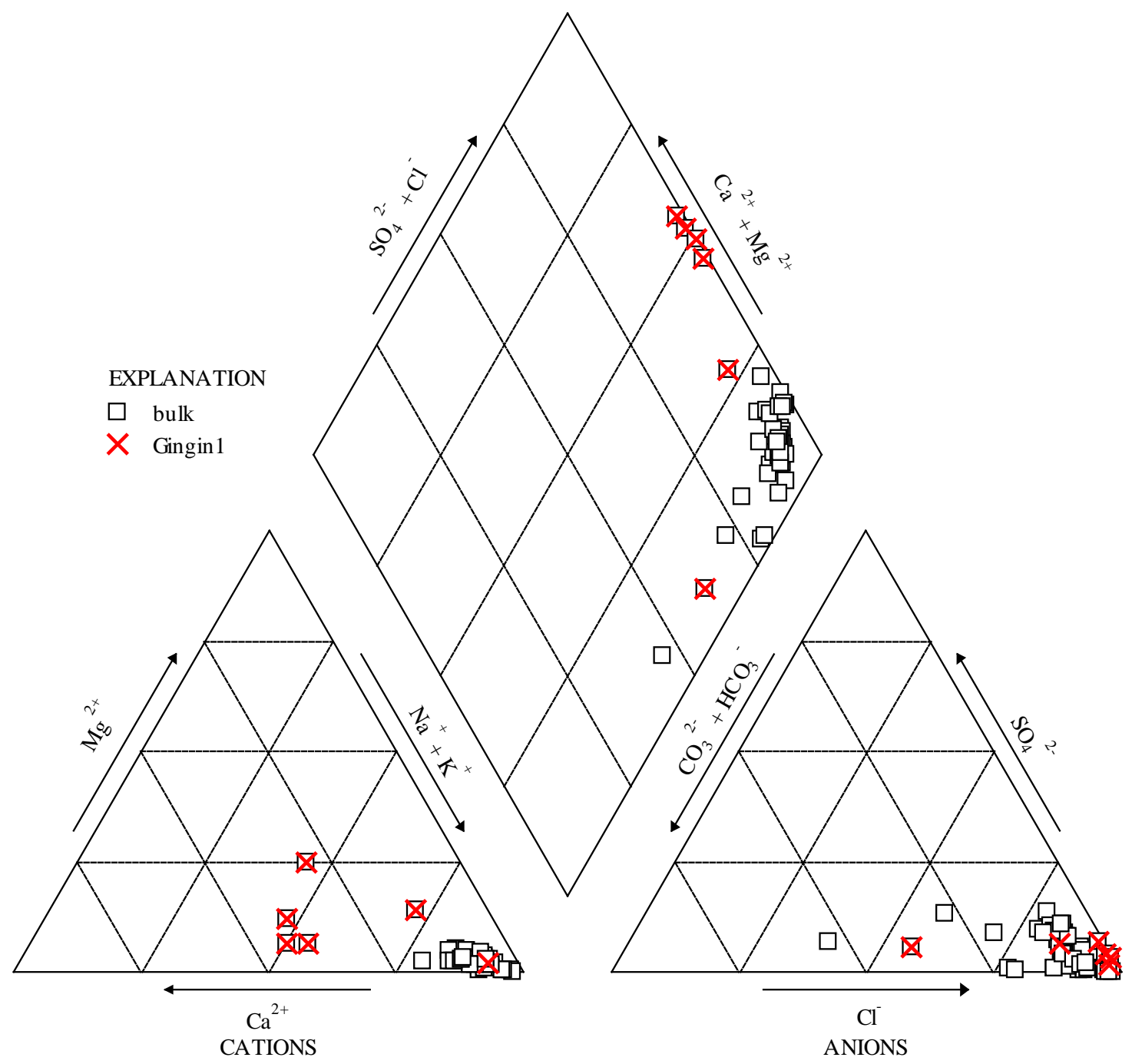

Figure 5

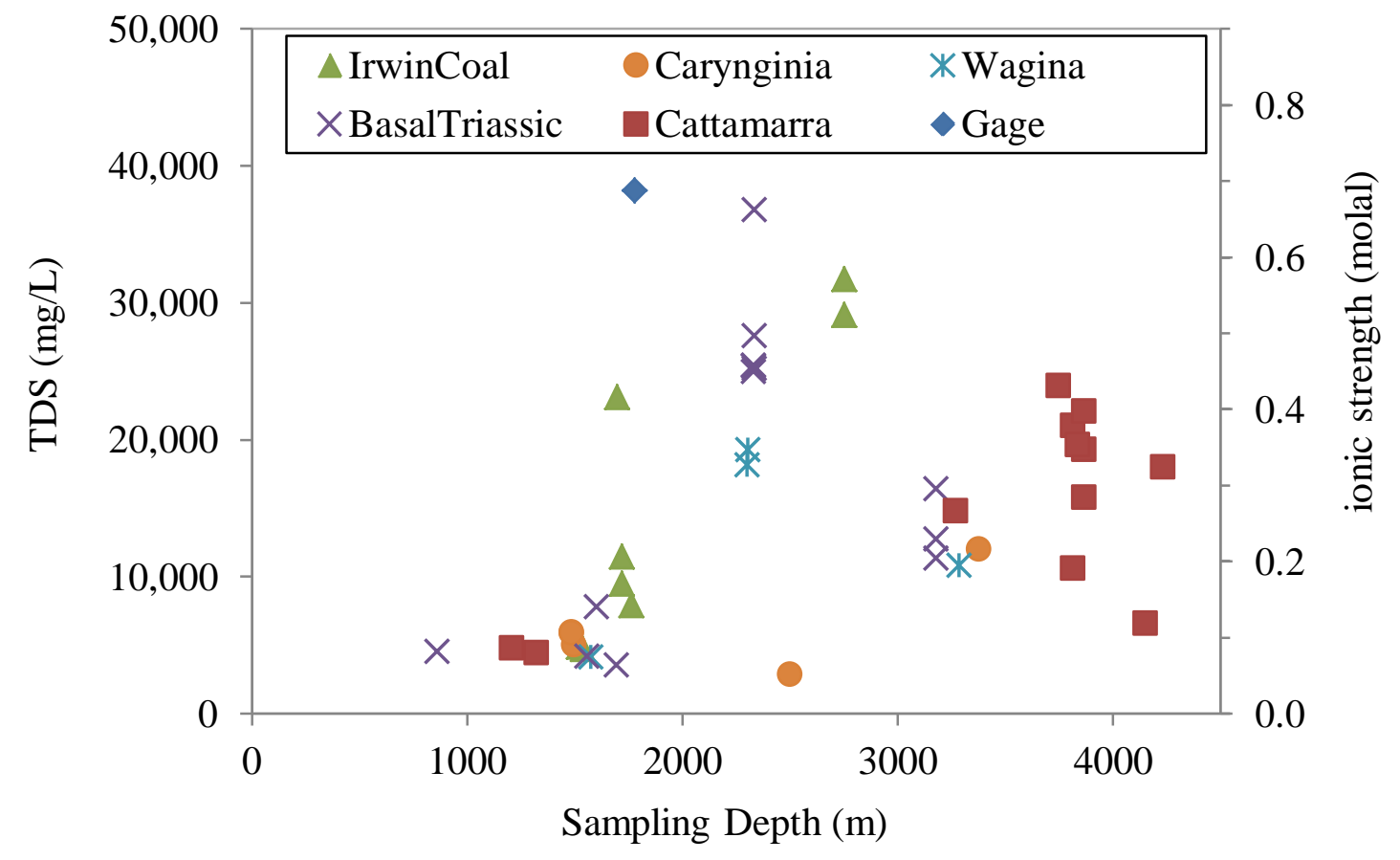

Figure 6 

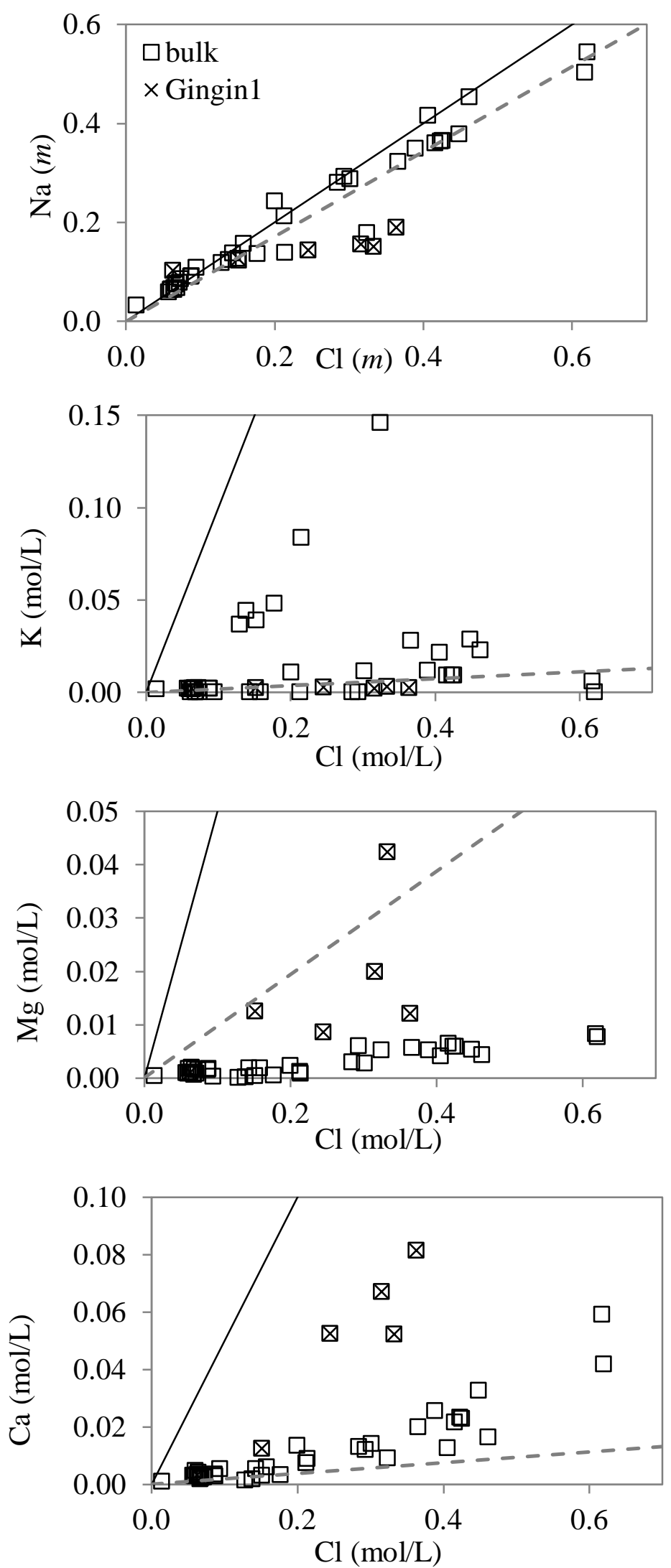

Figure 7 


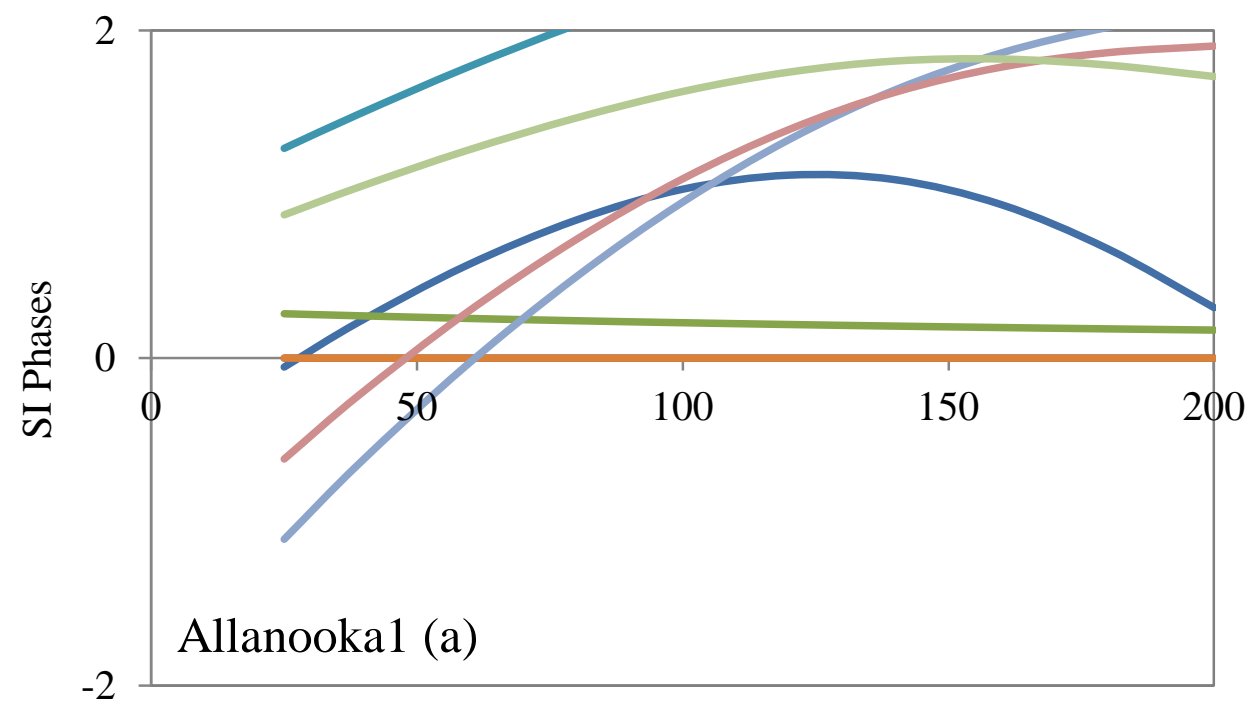

—si_Quartz

— si_Chalcedony

— si_Muscovite

_si_Kaolinite

—si_Calcite

— si_Paragonite

_ si_Albite si_K-feldspar

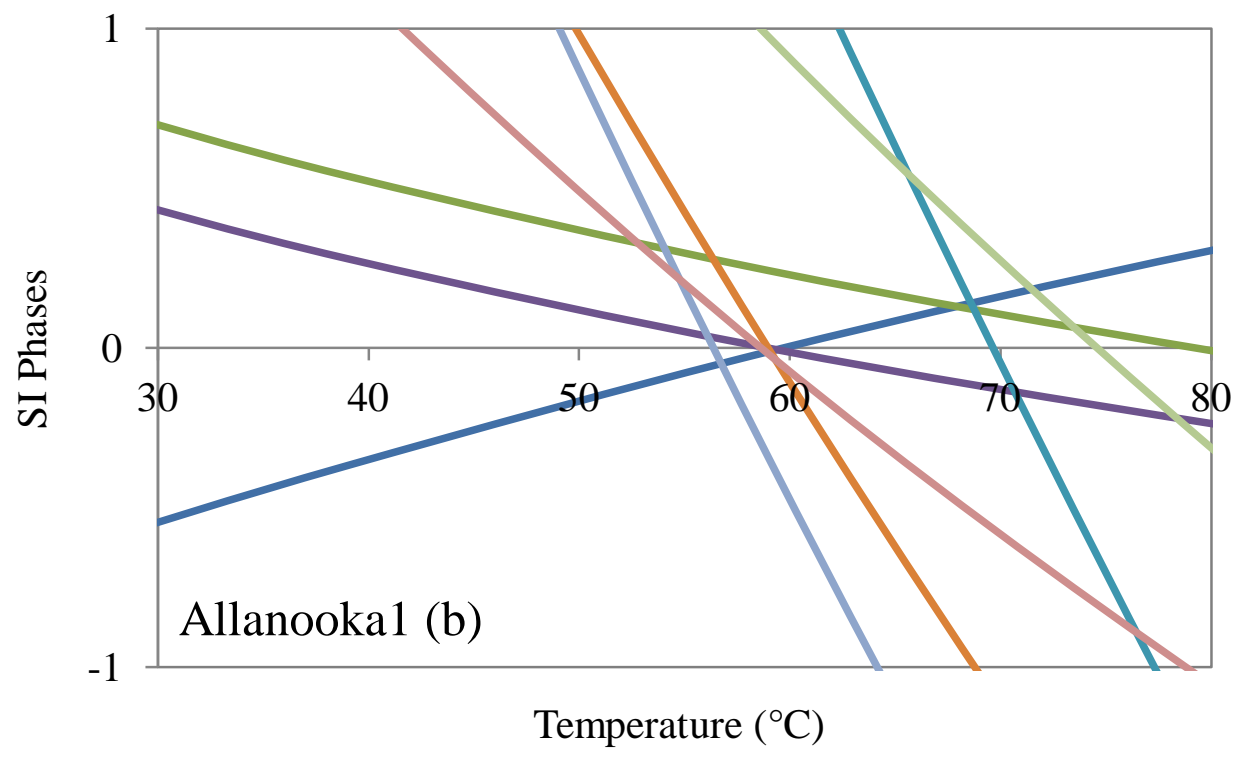

Figure 8 

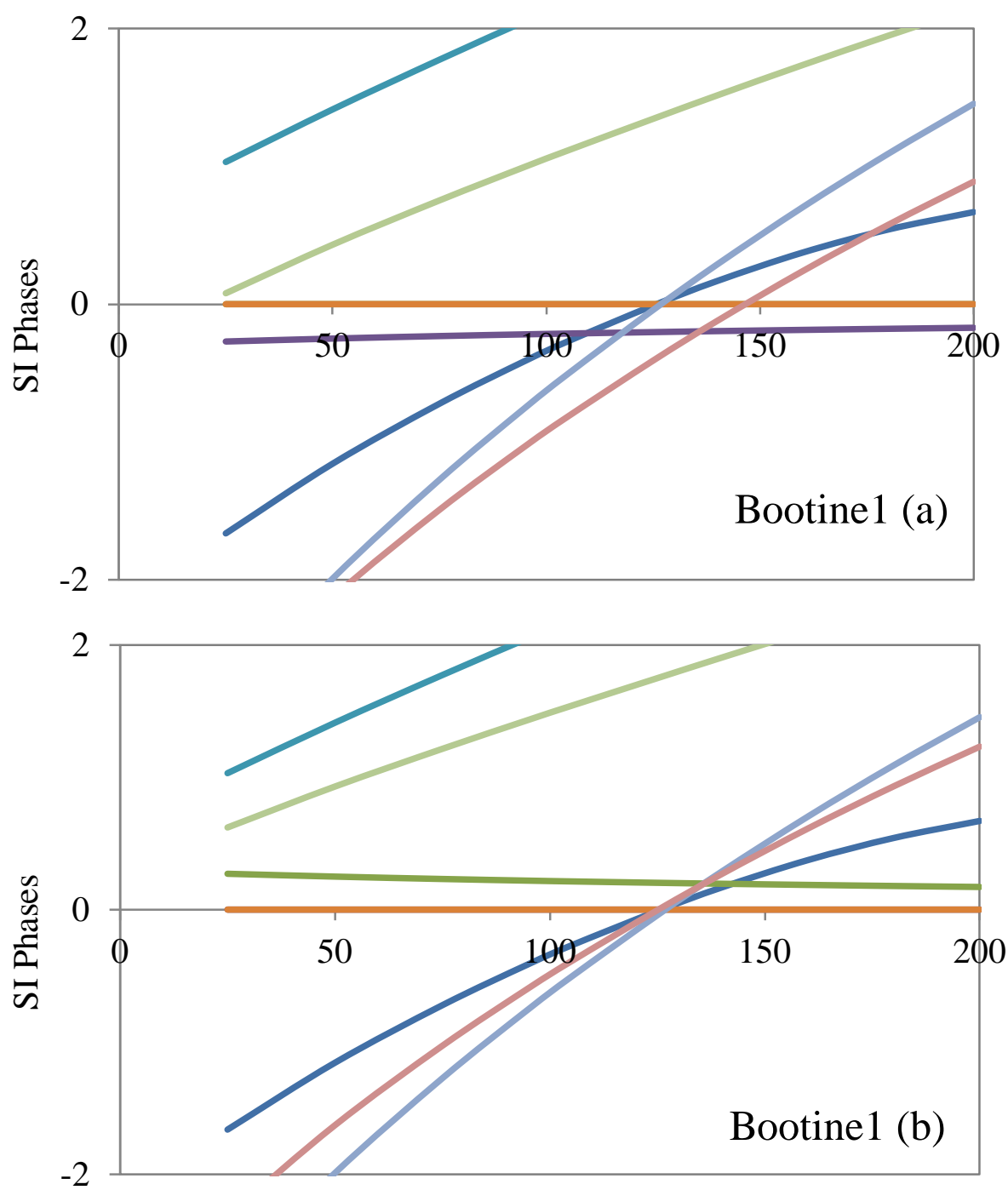

-si_Quartz

— si_Chalcedony

-si_Muscovite

- si_Kaolinite

— si Calcite

_ si_Paragonite

_si_Albite

si_K-feldspar

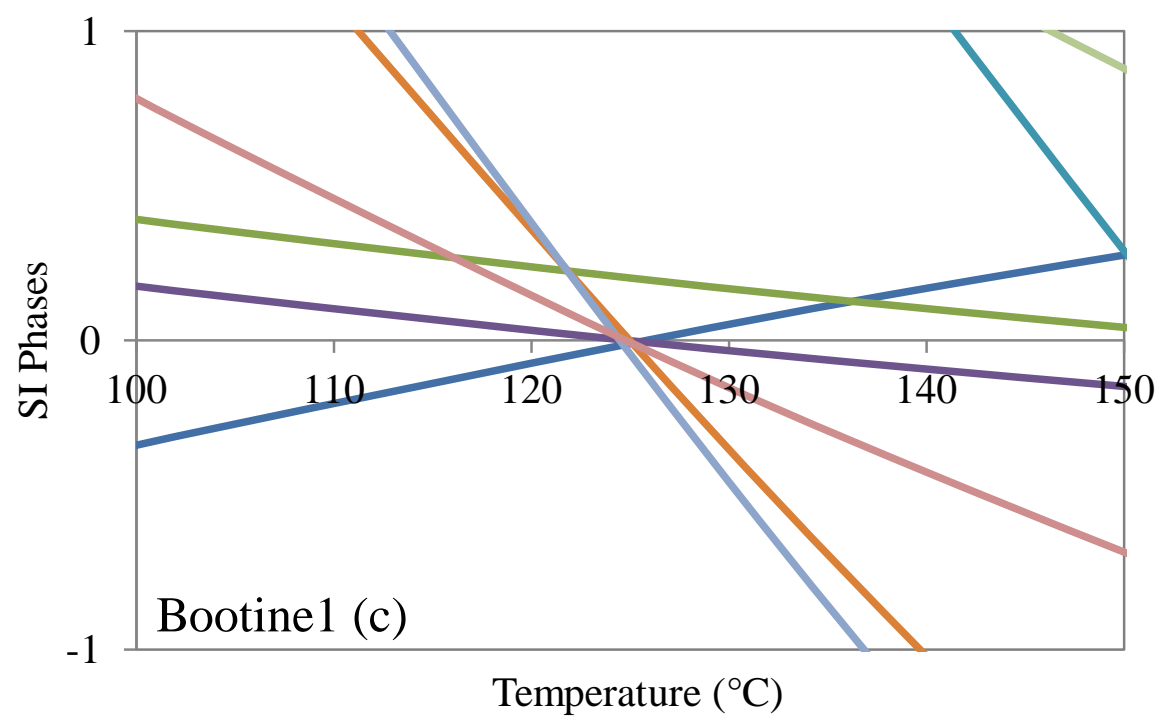

Figure 9 


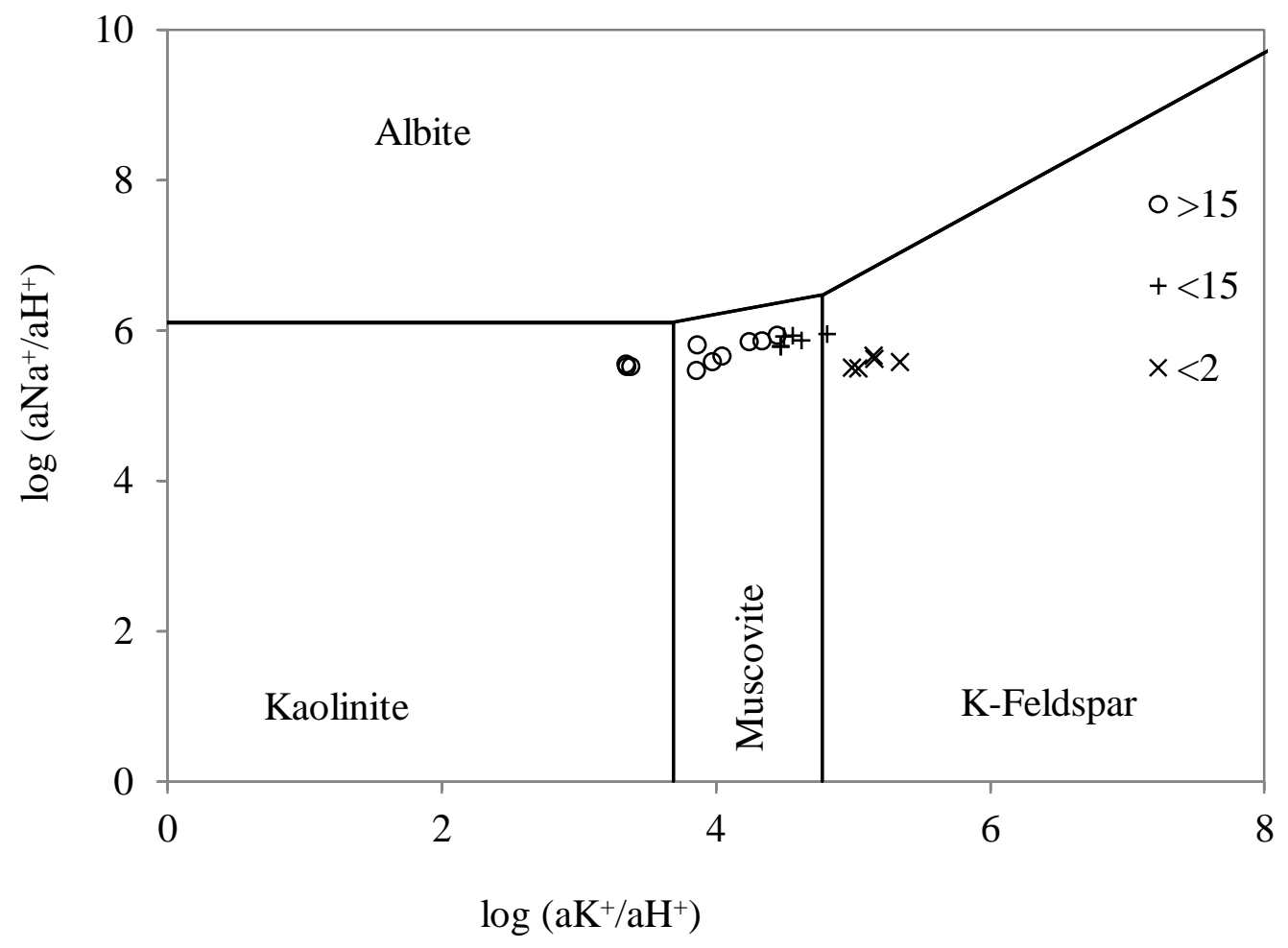

Figure 10

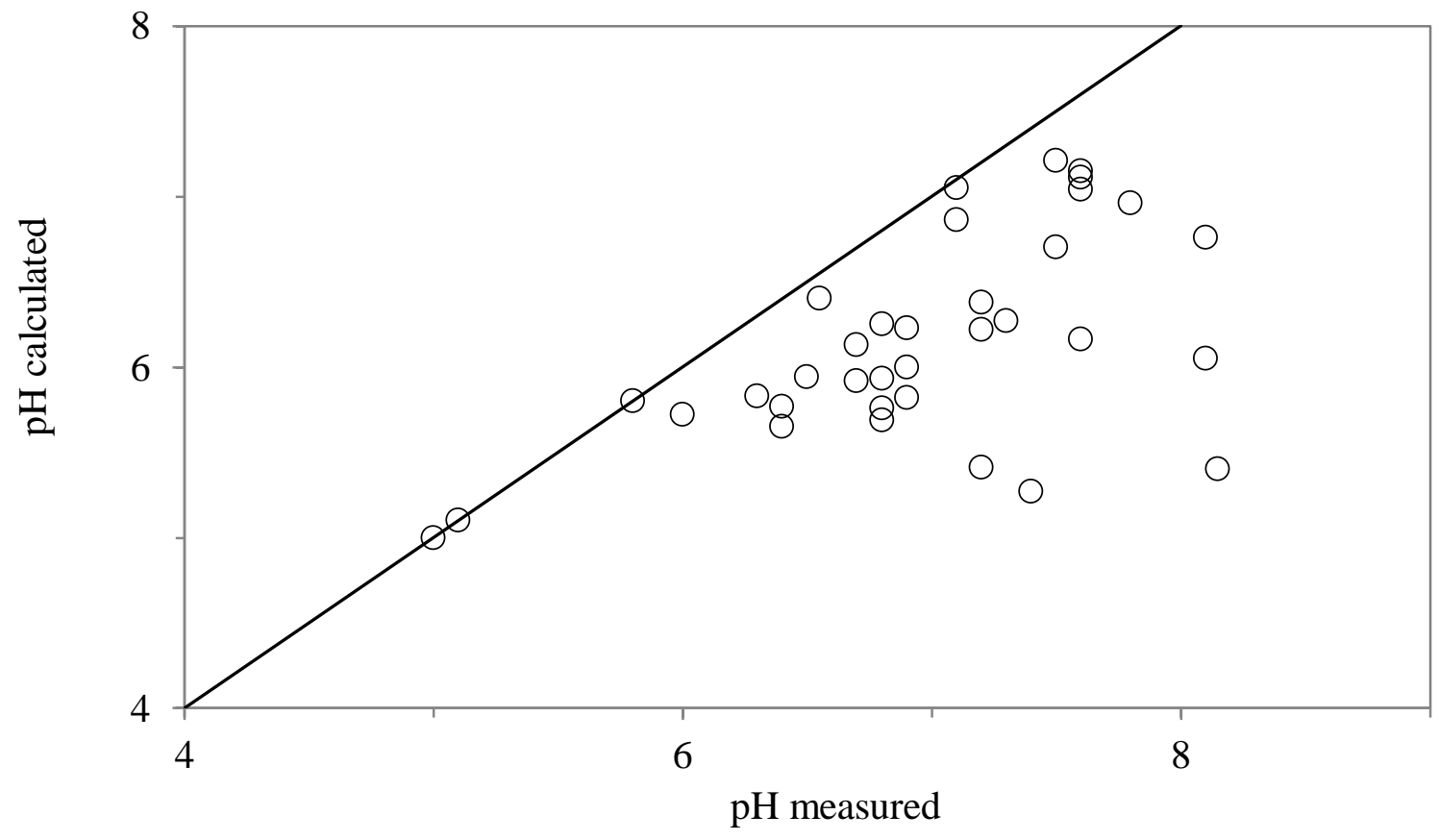

Figure 11 


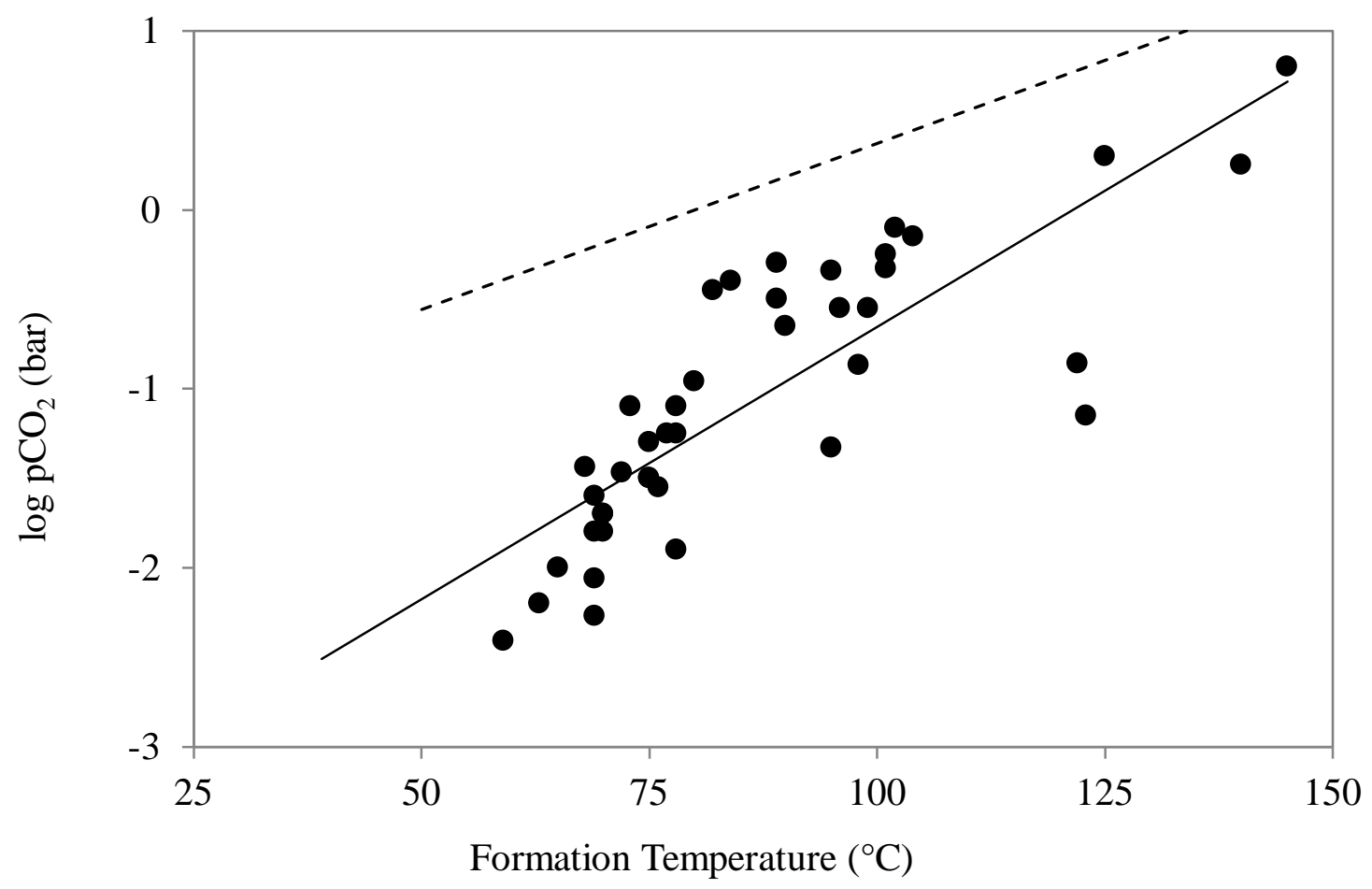

Figure 12

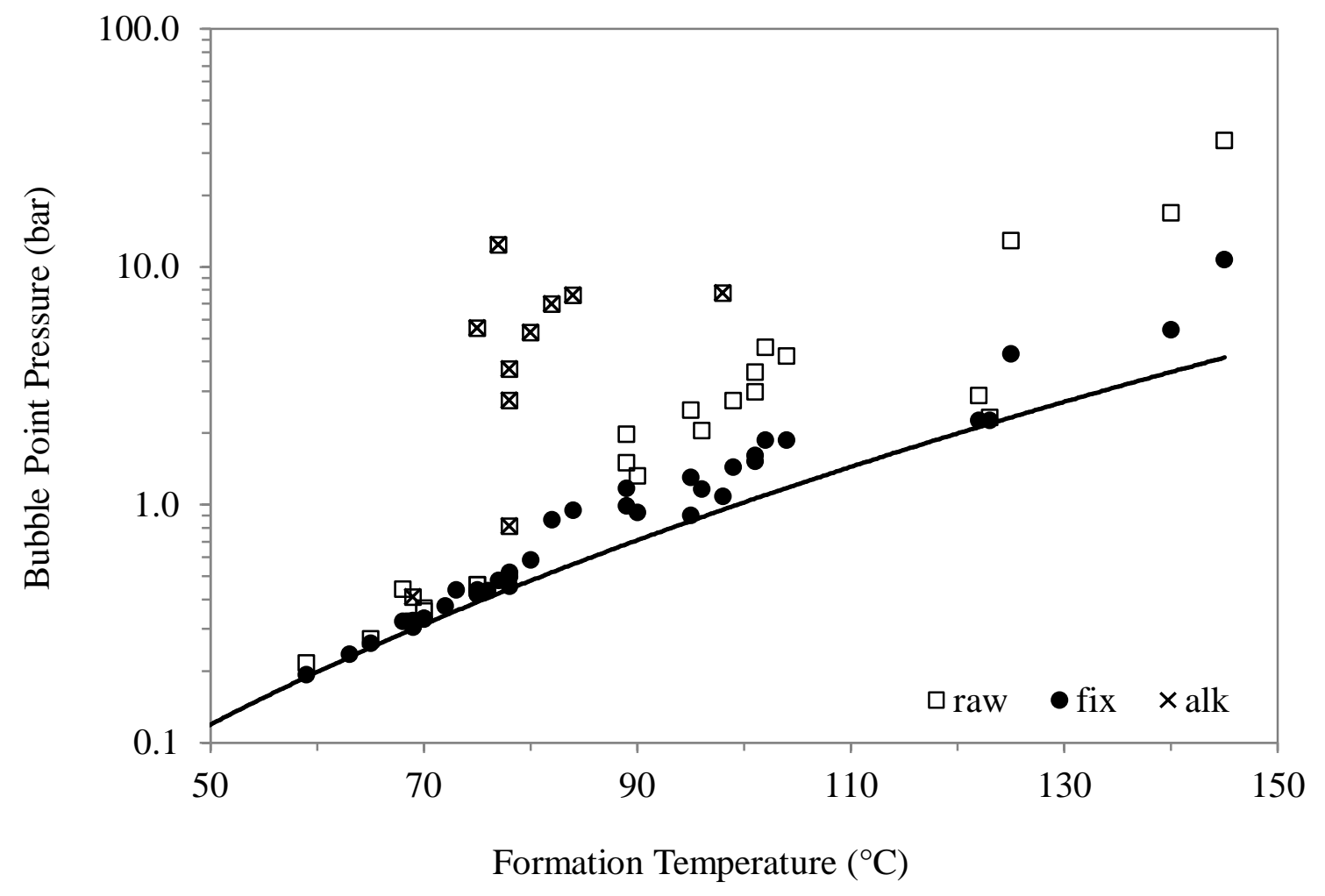

Figure 13 


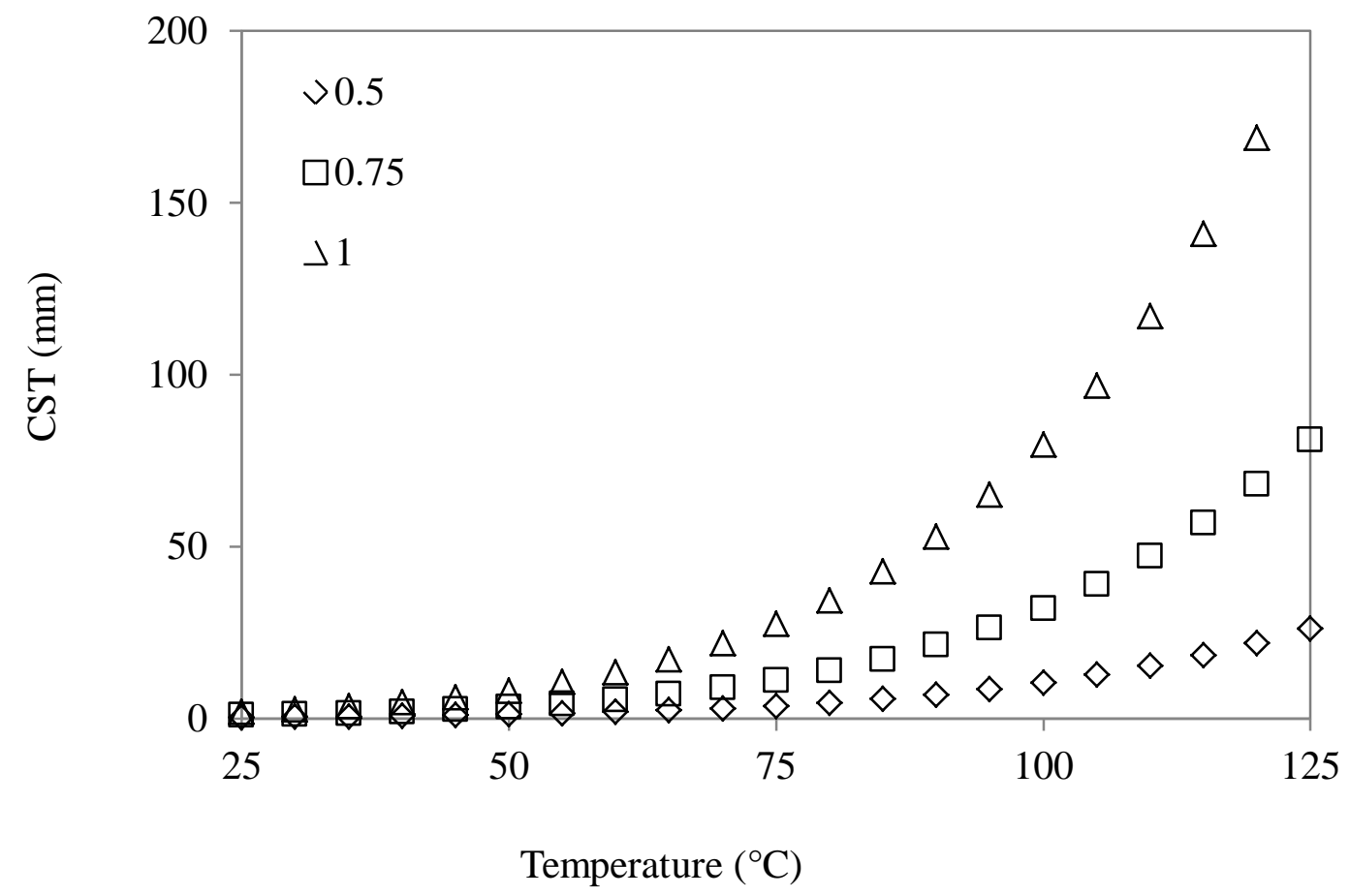

Figure 14 